\title{
El problema de la normalización en tres debates: Historización, Historikerstreit y Goldhagen
}

Nicholas Rauschenberg*

Resumen: En un contexto de revisionismo histórico es esperable que haya disputa en torno a riesgos de resignificación política sobre los temas abor-dados. Sin embargo, cuando el objeto de discusión es la violencia política suele ser más problemático desafiar cierto canon, dada su carga moral en otras esferas de validez discursiva. Llamaremos aquí "normalización" al modo de "relativización" o resignificación de cierta culpa colectiva en relación a la violencia política. La normalización es una estrategia discursiva que busca trascender su intención original de revisión historiográfica al ganar la esfera pública en su multiplicidad significativa. Reconstruiremos en este artículo tres contextos donde podemos identificar distintos modos de normalización. El primero, se refiere al debate entre Broszat y Friedländer en torno a la Historización a partir de la Alltagsgeschichte (historia del cotidiano). El segundo se inscribe en el Historikerstreit o querella de los historiadores, y comienza con un debate público en el cual Habermas contesta a un artículo del historiador conservador Ernst Nolte que comparaba la Alemania nazi al stalinismo soviético en el contexto de la guerra fría. Finalmente, abordamos el debate en torno al bestseller de Daniel Goldhagen, que tuvo amplia repercusión en la esfera pública alemana, en el que se destaca una exagerada "culturalización" del antisemitismo alemán como causa única del Holocausto.

Palablas clave: Historización. Historikerstreit. Debate Goldhagen.

\footnotetext{
* Pesquisador do IEALC (Instituto de Estudos para a América Latina e do Caribe) da Universidade de Buenos Aires (UBA). Doutor em Ciências Sociais na UBA com bolsa do Conselho Nacional de Investigaçóes em Ciência e Tecnologia da Argentina (CONICET). Foi bolsista de doutorado "sandwich" do DAAD na FU-Berlin. E-mail: nicholasrauschenberg@yahoo.com.br.
} 


\section{Introducción}

El "revisionismo" en general es donde memoria e historia más encuentran ambigüedades y divergencias. Los muchos "revisionismos" históricos generaron y aún generan debates marcando reconfiguraciones políticas y metodológicas en la historiografía contemporánea. Un debate revisionista suele trascender la esfera académica y, desde sus márgenes, donde la historia se enfrenta a los núcleos y matices de la memoria colectiva, parece generarse una actualización y toma de posición, una catarsis que renueva el sentido histórico, le exige autocrítica y el esfuerzo de esmerar sus tesis y presupuestos. Como explica Enzo Traverso, las revisiones cuestionan o polemizan una consciencia histórica compartida, sea la de una identidad o de culpabilidad:

[S]e refieren siempre a sucesos fundacionales - la Revolución Francesa, la Revolución Rusa, el fascismo, el nazismo, la guerra árabe-israelí de 1948, etc. - y su relectura de la historia concierne, mucho más allá de la interpretación de una época, nuestra forma de ver el mundo en el que vivimos y nuestra identidad en el presente (TRAVERSO, 2011, p. 108).

Aunque algunas revisiones puedan resultar fructíferas, es decir, puedan tener una connotación claramente positiva para el campo historiográfico, otras pueden oscilar de "discutibles" a "nefastas". Si François Furet (1980) propone desde una perspectiva liberal una revisión del sentido "revolucionario" de la Revolución Francesa argumentando que ésta en realidad fue una fuente de totalitarismos, una tesis discutible, más allá de su alcance político e ideológico y sobre todo en términos metodológicos, Ernst Nolte y Andreas Hillgruber, a su vez, proponen una lectura autodenominada revisionista con la casi exclusiva finalidad de relativizar los crímenes del nacionalsocialismo forzando justificaciones históricas y comparaciones moral y metodológicamente insostenibles. Aquí nos ocuparemos de los debates y revisionismos relativos al nacionalsocialismo.

Así, en este artículo se abordarán tres debates que marcaron, cada uno en su contexto, una apertura desde la "corporación de los historiadores", por así decirlo, hacia la esfera pública alemana. 
El primero es el debate en torno a la historización [Historisierung], específicamente el debate sobre las consecuencias morales y metodológicas relativas al uso de la Alltagsgeschichte entre Martin Broszat y Saul Friedländer (I). El segundo debate es el así llamado Historikerstreit - o querella de los historiadores - que tuvo inicio cuando Habermas contestó con una carta pública en el periódico Die Zeit a lo que llamó la "coalición" de los historiadores conservadores (II). El tercer y último debate es de lejos el que más tuvo repercusión en la esfera pública, no sólo de Alemania: el debate Goldhagen, a partir de la recepción alemana del libro Los verdugos voluntarios de Hitler. Los alemanes corrientes y el Holocausto, de Daniel Goldhagen (III). Las preguntas que intentaremos responder y articular son: ¿Cómo actúan los presupuestos morales de la memoria colectiva en los debates? ¿Cuál es la diferencia entre "relativizar" una premisa y "descontextualizar" una conclusión moral para forjar una interpretación con pretensión de validez científica? ¿Cómo es posible ampliar y tornar más compleja la percepción no sólo historiográfica, sino también político-moral, relativa a la memoria del período nacionalsocialista?

\section{Historisierung. Normalización por anacronismo}

La Alltagsgeschichte - o historia del cotidiano - es una metodología que aborda la conducta diaria de hombres y mujeres y cómo éstos "[...] se apropiaban de las situaciones en las que se encontraban" (LÜDTKE, 1995, p. 50). Ese método parece en un primer momento tratar de cubrir la brecha dejada, por un lado, por la historiografía marxista de Tim Mason (1993; 1995) limitada en su paradigma funcional-estructuralista a la noción de lucha de clases y, por otro, por la tradicional historiografía positivista que tiene por objeto los hechos y sujetos "de arriba", "la historia de los grandes hombres y acontecimientos políticos", lo que Alf Lüdtke llamó Ciencia social histórica [historische Sozialwissenschaft]. La Alltagsgeschichte se consolidaría en el contexto de los debates historiográficos alemanes buscando problematizar de qué modo logró imponerse el dominio nazi no sólo "desde arriba", sino principalmente cómo se "(co)producía al mismo tiempo desde abajo" (LÜDTKE, 1995, p. 60). El foco ahora 
estaba puesto en las condiciones que permitieron una "aceptación en masa de la dictadura, la guerra y los delitos” (LÜDTKE, 1995, p. 53). Sin embargo, no hubo una ruptura radical con el estructural-funcionalismo, sino sólo un cambio de enfoque que, dejando la preeminencia del marxismo, buscó, por un lado, mostrar diversas esferas de la sociedad en sus aspectos cotidianos, como las actividades de las mujeres, la relación de los alemanes con los extranjeros esclavizados, la vida eclesiástica entre otros recortes posibles más allá de su consciencia de clase y participación política. Por otro lado, la Altagsgeschichte permitió profundizar y revisar las investigaciones en torno a fenómenos arraigados en el imaginario social alemán de la época, como la resistencia [Resistenz y Widerstand] al régimen: no sólo las abiertamente politizadas como los distintos grupos de partisanos de los países invadidos (Widerstand), sino también las que sólo indirectamente afectaban al régimen (Resistenz), como en la iglesia, servicios sociales, etc. (ver BROSZAT, 1986). En relación a los alemanes, más que una resistencia activa y parcialmente organizada, como propuso Timothy Mason, hay que pensar en víctimas y coautores en situaciones extremadamente contingentes: "[...] son decisivos los múltiples tonos grises, las mezclas en las que algunos se convirtieron en coautores y coautoras, sin serlo permanentemente" (LÜDTKE, 1995, p. 68). Las conductas tenían altos y bajos en relación al apoyo al régimen: "entusiasmo y disposición colaboracionista inicial que se tornaron distancia, escepticismo o incluso resistencia a partir de la segunda mitad de la guerra" (LÜDTKE, 1995, p. 68).

Por más que la condena moral al nazismo sea insospechada $y$ absolutamente justificada, los historiadores se enfrentan a la pregunta por la imputabilidad de su objeto de estudio en el contexto de la investigación (ver HABERMAS, 2001). En el caso de la historia del cotidiano de los alemanes durante el dominio nacionalsocialista, ¿relativizar la imputación del objeto significa necesariamente hacer apología al nazismo, justificar ciertas conductas "normalizadas" o corroborar tesis negacionistas? ¿No sería una decisión también previamente justificable basarse en las posiciones, intenciones y consecuencias políticas a las que están sujetas las publicaciones de trabajos académicos? En un corto artículo publicado en 11 de agosto de 1986, Jürgen Habermas reconoce que parecía inevitable que 
muchos alemanes se "identificaran" con sus compatriotas del lado oriental y hasta con el ejército nazi [Wehrmacht]: "[...] es quizá una perspectiva válida para los veteranos [de guerra], pero no para un historiador que escribe 40 años después" (ACHA, 1995, p. 125). Esa "identificación", reivindicada por el historiador conservador Andreas Hillgruber, conlleva a que se deje de considerar la preeminencia del punto de vista de las víctimas como acceso moral más justificado al estudio de la época del nacional-socialismo. Esa identificación fue objeto de discusión en dos debates sobre el Tercer Reich en razón de su “descontextualización”, una metodológicamente justificada, otra políticamente intencional, que desplazaba el eje de la victimización a los alemanes que sufrieron la guerra en vez de las víctimas del Holocausto, justificación moral y políticamente preeminente. Pese a ser considerada una disputa restringida al campo metodológico de la historiografía, la relativización de la carga moral de los recortes investigativos de esa vertiente de la historiografía alemana abrió camino a que los historiadores conservadores (M. Stürmer, A. Hillgruber, E. Nolte, etc.) rescataran selectivamente para su "historia nacional" y debidamente "occidentalizada" aspectos que pudieran relativizar la "culpa de los alemanes". Sin embargo, antes de ocuparnos de la querella de los historiadores [Historikerstreit], nos ocuparemos ahora del debate en torno a la historización [Historisierung] y la historia del cotidiano entre Saul Friedländer y Martin Broszat.

Martin Broszat [1926-1989] fue un historiador alemán que vivió en la Alemania nazi aunque no se haya involucrado políticamente con el nazismo. Saul Friedländer [1932-], historiador israelí, nació en Praga siendo hijo de una familia de judíos alemanes asesinados en Auschwitz. Sobrevivió a la guerra exiliado en Francia, de donde sus padres fueron deportados. Broszat defendía que la historización abría la posibilidad de poner el pueblo alemán en contacto con su historia en primera persona: hasta entonces el abordaje parecía restringido a un pueblo extrańo para sí mismo, con preeminencia de la tercera persona. Como explica Dominick LaCapra, "Broszat construye la historización en términos de la inserción de los nazis en el amplio contexto de la vida cotidiana, que a veces proseguía con relativa tranquilidad, sin que la alterara lo que ocurría en los campos de concentración y de exterminio" (LACAPRA, 2007, p. 188). Sin 
embargo, Friedländer veía una relativización generalizada en esa integración de la vida cotidiana en razón de los problemas morales que conlleva la especificidad del nazismo. Más que una "ampliación del enfoque”, Friedländer está preocupado con el mero cambio: que Auschwitz y el exterminio perpetrado por los nazis pierdan su centralidad, es decir, que la tesis de la "primacía de la política" que derivó en el Holocausto quede atenuada, relativizada o normalizada ante el nuevo enfoque (FRIEDLÄNDER, 1987). Podríamos añadir que la primacía no es sólo de la política, sino también de la moral. El embate puede ser puesto en la clave dicotómica sugerida por Dominick LaCapra: "Auschwitz es/no es el suceso central/punto cardinal de la época nazi” (LACAPRA, 2007, p. 192).

El debate puede ser resumido en dos grandes cuestiones. La primera se refiere a esa "ampliación de enfoque" que busca profundizar la diversidad de la comprensión empática de la experiencia. Para eso, Broszat publica en 1985, en la importante revista Merkur, un alegato [Plädoyer] en favor de un abordaje interdisciplinar para la historización de la Alemania nazi (BROSZAT, 1985). En la búsqueda por una "historia crítica" y una "historia como ciencia social", Broszat propone distinguir historische Einsicht (comprensión o intelección histórica) del conocido recurso de la hermenéutica de Gadamer, el Verstehen (entendimiento o comprensión). En su primera carta a Friedländer, Broszat afirma que la historización de ningún modo corre el peligro de "relativizar" los crímenes del nacionalsocialismo (BROSZAT; FRIEDLÄNDER, 1988, p. 341). Broszat veía que el período nacional-socialista continuaba siendo como una isla en la historia contemporánea [Zeitgeschichte] alemana. Como explica Ian Kershaw, el Tercer Reich se convirtió en "[...] un recurso para obtener lecciones de moralidad política, donde la rutinaria condena moral excluye la comprensión histórica, reduciendo al nazismo a una anormalidad" (KERSHAW, 2013, p. 289). En este sentido, Broszat sostiene que una distancia crítica es imprescindible, y rechaza tanto un historicismo clásico como el del siglo XIX que busca un entendimiento global como la "fusión de horizontes" de un enfoque apenas hermenéutico que recaería en una posible "identificación" y posterior "normalización". Lo que busca Broszat es una objetivación distanciadora que elimine la posibilidad de una "normalización de la consciencia histórica”, especialmente instrumentalizaciones políticas 
como las de Ernst Nolte en el contexto del Historikerestreit. Friedländer, en su primera respuesta, le reprocha a Broszat en este punto con el exagerado ejemplo del trabajo de Andreas Hillgruber sobre los alemanes en el frente oriental. El historiador judío advertía que la historización se apoyaba en una relativización y normalización de la era nazi: de una historización (Historisierung) se podría pasar a un historicismo (Historismus) relativizante (KERSHAW, 2013, p. 294). Sin embargo, el concepto de comprender (Nachvollziehen) de Broszat no es el peyorativo Verstehen que puede también signi-ficar entender, comprender, perdonar y justificar. El Nachvollziehen entendido como intelección histórica debe, antes, permitir, por un lado, una aproximación iluminadora cuya objetivación se enfrenta necesariamente a la mera identificación, dada la especificidad ineludible del período estudiado. Por otro, debe comprender la magnitud criminal de ese pasado pero en su contexto, y teniendo en cuenta la imposibilidad de esquivarse de las cuestiones político-morales que suscita el pasado reciente. El Proyecto Baviera ya había mostrado algunos resultados de la Alltagsgeschichte (ver BROSZAT et al., 1983). Más allá de encontrar por debajo de la barbarie algunos patrones de "normalidad social", como temía Friedländer, muchos de ellos eran anteriores y sobrevivieron al régimen hitlerista. Queda así inevitablemente relativizado el papel de la ideología nazi al abordar lo que podría llamarse una "normalidad cotidiana", pero en favor de una complejización de factores sociales antes, durante y después del nazismo. Lo que el autor israelí le reprocha en este punto es que "se produciría un inevitable deslizamiento en el foco hacia el problema de la modernización" dejando de lado los acontecimientos y decisiones relativas al gobierno nazi (KERSHAW, 2013, p. 297). No obstante, Gisela Bock (1986), historiadora que investiga el nazismo en el cotidiano desde una perspectiva de género, muestra una asociación directa entre el antifeminismo nazi y la política racial por medio de un análisis de la esterilización compulsiva y "tratamientos especiales" [Sonderbehandlungen] para aquellos que tuvieran enfermedades hereditarias. Antes que "relativizar" la agencia y la culpabilidad de los sujetos, Bock presenta un análisis de la ideología con un estudio de caso que abre nuevas perspectivas desde las fisuras sociales del régimen. La "primacía de la política" se ve en realidad reforzada pero puesta en un nivel de mayor complejidad. Se 
diferencia de la "primacía de lo moral", que es lo que busca acentuar a su modo Friedländer. La "desmoralización", sobre todo entre los historiadores, es el eje del debate. ¿En qué medida "repolitizar en otros términos" encuentra validez al descargar la previa moralización sobre la historia del nacionalsocialismo y la Solución Final?

La segunda cuestión es sobre el límite del distanciamiento historiográfico y su separación inmanente de la memoria social e individual. ¿Sería el período nacionalsocialista simplemente "historia", es decir, algo ya pasado, sobre todo entre 1985 y 1987, cuando se daba ese debate? En su primera carta, Broszat habla de una "superación del pasado" [Vergangenheitsbewältigung], por lo menos en la República Federal de Alemania: no existen, por un lado, más razones suficientes para seguir con una "cuarentena general" como en los años 1950 o 1960, donde se daba una interpretación asumidamente demonológica del régimen ilegítimo, ni tampoco, por otro, la “necesidad de acusar y condenar, porque ya no hay más personas a las que se las pueda considerar como directamente responsables y porque también entre tanto, las diferentes consternaciones provocadas por el frente nacionalsocialista de aquel entonces se han borrado de la sociedad de la República Federal" (BROSZAT, 1988, p. 342). Sin embargo, eso no significa que la consciencia y culpabilidad moral de los crímenes del nacional-socialismo "sean llamadas a desaparecer", sino que ellas deben ser mediadas por una investigación cuidadosa y resistir a los intentos de "racionalizar" ese pasado (BROSZAT, 1988, p. 342). Uno de esos modos de racionalizar el pasado es la memoria. Quizá este sea el punto más débil del planteo de Broszat: cuando distingue entre registro historiográfico y "recuerdo mítico", el de las víctimas. Para Broszat no le corresponde sólo a los historiadores alemanes investigar el pasado nacional-socialista, sino que en razón de la persecución de millones de personas, ese régimen puede y debe ser abordado por una infinidad de historiadores de distintas edades y nacionalidades. Además, ese período histórico está lejos de ser un pasado históricamente muerto para esos seres humanos y sus sobrevivientes, sus memorias y monumentos:

[L]o que distingue la exploración científica de ese pasado es el hecho de saber que aquél está todavía cubierto de monumentos 
de conmemoración desconsolados y acusadores, todavía señalan sentimientos dolorosos de numerosos individuos, particularmente judíos, que tienden a conservar una forma mítica de ese recuerdo (BROSZAT, 1988, p. 343, subrayado mío).

En su propuesta de Historisierung, ¿no considera Broszat la memoria colectiva como los entonces ya conocidos trabajos de Maurice Halbwachs y Pierre Nora? ¿Los estudios académicos que tienen la memoria de las víctimas como objeto no serían más que reverberaciones de formas miticas de recuerdo? Esa es la inquietud y quizá irritación de Friedländer en su primera carta a Broszat.

La simple separación de cuarenta a cincuenta años "[...] no confiere todavía carácter histórico al período nazi” (BENZ, 1988, p. 33). Dan Diner también pone en duda si el nacionalsocialismo es efectivamente "historia superada", no sólo metodológicamente, sino también y sobre todo políticamente. Teniendo en cuenta el planteo de Broszat de que el recuerdo de las víctimas sería un recuerdo mítico, podríamos sugerir lo contrario. Pensando en la idea de "historia natural" [Naturgeschichte] de Theodor Adorno (1991), podríamos sugerir que con Broszat la metodología de la historización se ha convertido en una suerte de mitología para esquivarse de la monstruosidad y el horror de Auschwitz. Separar fríamente la primacía de la política de la primacía de la moral genera ese efecto, especialmente si se cuestiona la legitimidad del discurso de las víctimas. Se corre el riesgo de despolitizar la política que prometía evidenciarse. No sin falsa ingenuidad Ernst Nolte reivindica la posibilidad de "comparación” entre los horrores de Alemania y Rusia pensando en una "renacionalización" [Renationalisierung] de la historia (DINER, 1987, p. 154). Diner también advierte que la historización no deja de ser un modo de "renacionalización" de la cotidianidad nacionalsocialista con su enfoque en la normalidad y banalidad del Tercer Reich (DINER, 1987, p. 158). Lo que Broszat quiere ver como "científico", puede en realidad ser una máscara, un filtro ideológico que impide ver lo terrible de la propia historia. Pensar el nazismo a partir de abstracciones como la "modernidad", "sociedad industrial" o hasta "capitalismo" (como quiere Nolte), no deja de ser un modo de exculparse, de negar parcialmente la gravedad del horror (DINER, 1987, 
p. 159; PEUKERT, 1987, p. 152). En su texto sobre la resistencia al nacionalsocialismo, Broszat prácticamente no menciona trabajos dedicados a las estrategias individuales y de pequeños grupos de resistencia (sabotaje, atentados etc.) para defender un abordaje que privilegie "tipos ideales", abstractos y clasificados según el desarrollo del Tercer Reich (BROSZAT, 1986, p. 295). Los tipos ideales o "principales" [Haupttypen] son los "comunistas", "partisanos", "socialistas", "élite conservadora” o "milieu religioso-eclesiástico" y en casi ningún momento se contextualizan las estrategias y contingencias, o siquiera acciones concretas de la resistencia. De ningún modo la resistencia está vista desde el punto de vista de las víctimas, de los que por resistir fueron perseguidos y muchos de ellos asesinados.

Aunque Broszat no niegue que ambos discursos son válidos (el científico y las memorias de las víctimas), no ve como posible integrar ambas perspectivas y sentencia que la memoria no es útil a la mirada histórica. Defendiendo la preeminencia de la memoria, Friedländer le reprocha que "cuando nos acercamos al inmenso campo de la criminalidad nazi, el deber del historiador es quizás anticipar el intento de visualizar, precisamente como para que él pueda cumplir su tarea en término de precisión documental y de interpretación de los eventos" (BROSZAT; FRIEDLÄNDER, 1988, p. 371). Pese a que Broszat "demuestre" que hasta los juicios de Nuremberg Auschwitz no era ni de lejos la principal preocupación de los aliados, resultaría improbable creer que ese descubrimiento no hubiese cambiado el eje de interpretación de la guerra de modo más que justificado entre los historiadores. El comentario de Friedländer plantea la cuestión de la "supresión" y la "represión" por parte de la población alemana ante la reconstrucción de la "normalidad" que supone una ignorancia generalizada sobre el exterminio en los campos. Si se considera la memoria como válida es imposible que, una vez que los alemanes hayan tenido consciencia de Auschwitz aun después de la guerra, sea pensable que su comprensión individual sobre el período nacionalsocialista no haya cambiado, sea como vergüenza, negación o autocrítica. Broszat recae en un planteo no sólo historicista, sino también anacrónico al descontextualizar artificialmente las memorias. La aporía de Broszat nos lleva de nuevo a LaCapra: "Auschwitz es/no es el suceso central/punto cardinal de la época nazi" (LACAPRA, 
2007, p. 192). Historicizar el pasado exige que nos situemos como involucrados de modo inmanente con esos hechos, es decir, "en relaciones de transferencia con el pasado" (LACAPRA, 2007, p. 195). Aislar los hechos políticos y desnudarlos de su peso moral no sólo despolitiza sino que ofende a la memoria e historia de las víctimas por tornar "lo moral" un término peyorativo. La justificación de la Historisierung, más allá de sus relativos aportes a la historia alemana, falla por su anacronismo disfrazado de simulacro objetivista.

\section{Historikerstreit: normalización por '(re)contextualización'}

¿Qué significa "normalizar" hechos históricos de violencia política? ¿Cómo en los debates sobre el sentido moral y político de hechos de violencia aberrante éstos son "relativizados" en el marco de una disputa metodológica y política? En los debates públicos en torno al carácter único del Holocausto, nunca falta un argumento que resbala hacia algún tipo de relativización. El negacionismo y la normalización actúan siempre articulando y por veces omitiendo distintas esferas discursivas de validez reproduciendo y distorsionando presupuestos semánticos con algún tipo de finalidad. La normalización es así una forma de negacionismo que justifica los hechos aberrantes como siendo propios de "un orden cultural", es decir, inevitables; es como si al revisitar ciertos acontecimientos desde cierta perspectiva histórica y con una determinada intencionalidad política ellos parecieran "infelizmente necesarios" y se podrían "comparar" con hechos "parecidos" para indicar causas del orden de "la cultura" o de "la época" (ver COHEN, 2005).

El Historikerstreit fue una oportunidad para un acierto de cuentas historiográfico-político en el marco de la relación entre la historiografía alemana y la esfera pública, aunque, como veremos, el debate Goldhagen logró incendiar mucho más esa relación. La querella se dio en gran parte en cartas de lectores de los diarios FAZ (Frankfurter Allgemeine Zeitung) y Die Zeit, y giró en torno a cómo las tesis históricas autodenominadas "revisionistas" estarían relacionadas a 
la identidad, culpa y responsabilidad del pueblo alemán después del Holocausto. Nunca antes desde el final de la guerra se pudo hablar tan abiertamente en público sobre versiones encontradas en torno a las causas y los sentidos del nazismo. Por un lado, incentivados por el revisionismo histórico de Ernst Nolte en obras como Der Faschismus in seiner Epoche (ver NOLTE, 1963), los historiadores Klaus Hildebrand, Michael Stürmer y Andreas Hillgruber (llamados irónicamente "la nueva coalición de los historiadores"), buscaron relativizar, cada uno con su trabajo, la exclusividad del horror de los campos de concentración y exterminio. Su estrategia narrativa era argumentar en favor de una "normalización" comparando el horror nazi a otras experiencias según ellos semejantes. Se efectúa, por lo tanto, una normalización por medio de una estrategia retórica de relativizar el Holocausto. Por otro lado, Jürgen Habermas, Hans Ulrich Wehler, Jürgen Kocka, Hans y Wolfgang Mommsen, Martin Broszat, entre otros, más allá de defender la especificidad de la catástrofe nazi, buscaron evidenciar tanto la intencionalidad política en las estrategias argumentativas del primer grupo de autores como sus limitaciones teórico-metodológicas (KAILITZ, 2008, p. 8). Vale subrayar que estos historiadores, así como el filósofo Jürgen Habermas, son de una generación que vivió su infancia en la Alemania nazi. Esos autores nacieron entre 1923 y 1930, lo que le atribuye un especial carácter político y moral al debate.

El evento catalizador para el debate, más allá del flujo reciente de publicaciones revisionistas de aquél entonces, fue la conmemoración de los cuarenta años de la capitulación en el cementerio de Bitburg el 5 de mayo de 1985, que contó con la visita del entonces canciller de la República Federal de Alemania Helmut Kohl (CDU) y del entonces presidente de los Estados Unidos Ronald Reagan (PR). Muchos intelectuales rechazaron públicamente el evento debido a que cuarenta y nueve oficiales de las SS estaban enterrados allí. El escándalo llevó a que se hiciera un acto ceremonial similar como forma de compensación en el ex-campo de concentración de Bergen-Belsen (ACHA, 1995, p. 118). A partir de la experiencia de Bitburg, Habermas cuestionó además el proyecto del memorial que sería construido en el cementerio norte de Bonn. ¿Sería posible construir un monumento o memorial público independientemente de víctimas y victimarios? O aún, ¿sería posible homenajear victimarios y víctimas 
en el mismo contexto, en el mismo lugar, presuponiendo algún tipo de abstracción reconciliadora? ¿No sería una reconciliación forzada o inclusive una usurpación imponerle a las víctimas una indiferenciada forma de rememoración? (HABERMAS, 1988b, p. 26). Habermas acusó que en ese gesto se estaba "aflojando" el pasado nazi al mismo tiempo en que se "conjuraba una hermandad bélica anticomunista" que, en la "tradición alemana”, también significaría un vínculo con un resto de antisemitismo (KAILITZ, 2008, p. 7). Lo que denuncia Habermas es una apropiación "identificadora” de la historia, una identificación con un pasado que presupone una posición neutral a Alemania. Lo negativo de la memoria colectiva predominante que obstruye una identidad social pasa a ser nivelado una vez que se asume que, "bajo el signo de la libertad o del totalitarismo, el siempre virulento miedo al bolchevismo debe ser usado para mantener viva la correcta imagen del enemigo" (HABERMAS, 1988b, p. 27). El evento en Bitburg moviliza la conciencia histórica hacia un "sentimiento nacional". Y el caluroso saludo entre los generales veteranos de la SS y el presidente de los Estados Unidos podrían hasta confirmar que "los alemanes" han estado siempre del lado correcto contra el bolchevismo. El trasfondo político que sobresale es la histórica y aún actual "[...] complicidad del nacional socialismo y las élites locales, que constituyen el verdadero escándalo político que carga el nombre alemán” (ACHA, 1995, p. 120).

La preocupación por construir una identidad estable por vía de una nueva consciencia histórica parecía conmover a Michael Stürmer, asesor en ese entonces de Helmut Kohl (ACHA, 1995, p. 118). Para Stürmer, "en un país sin historia, quien controle la memoria, defina los conceptos e interprete el pasado, gana el futuro" (citado en HABERMAS, 1988b, p. 28). En su defensa de una historia políticamente consciente de su responsabilidad, Stürmer sostiene que el pluralismo de valores e intereses lleva "[...] tarde o temprano a una guerra civil si no se es capaz de encontrar una base común” (STÜRMER, 1983, p. 84). La historiografía, así, no debería resistirse a producir y diseminar una visión histórica que ayudara a fomentar un consenso nacional. Además, para Stürmer, el historiador debe apoyarse en métodos científicos que le permiten proveer su producción de significados y basar "desmitologizaciones" (HABERMAS, 1988b, p. 29). No sin 
ironía retoma Habermas esa supuesta misión de Stürmer sobre el oficio del historiador. Suena como mínimo contradictorio que desmitologizar resulte ser contiguo a proveer significados específicos con finalidades político-identitárias. ¿Desmitologizar para remitologizar? Esa sería la pregunta al intento cosificador de Stürmer. Un ejemplo de ese tipo de remitilogización vulgar es atribuirle importancia a la posición geográfica de Alemania como si eso provocara situaciones políticas y de guerra que de otro modo pudieran ser evitadas. En definitiva, Stürmer se lamentaba de no poder escribir un libro como F. Brudel, La identidad de Francia, donde el autor asume amar a Francia con lo que le gusta y lo que no. La referencia a Brudel no es ingenua: los historiadores conservadores preferían aspectos atribuidos a la longue durée antes que atenerse a detalles y coyunturas políticas claras. La longue durée además parecía permitir que se asumieran ciertas "tradiciones" como propias siempre que convenientes (ACHA, 1995, p. 138).

Pero es con la publicación Zweierlei Untergang. Die Zerschlagung des Deutschen Reiches und das Ende des europäischen Judentums (Dos caidas. La destrucción del tercer Reich alemán y el final del judaismo europeo), de Andreas Hillgruber (1986), que la operación política de relativizar el Holocausto se hace más explícita. Como interpreta Habermas, "destrucción" [Zerschlagung] requiere un oponente agresivo, mientras que "final" parece ocurrir con cierto consentimiento (HABERMAS, 1988b, p. 31). Si, por un lado, en el relato de Hillgruber el enfrentamiento del frente oriental ante las barbaridades del ejército rojo aparece como un bravo sacrificio, por otro, el exterminio en los campos de concentración aparecen como sucesos inertes organizados por los Einsatzgruppen. El Holocausto aparece aquí como una operación abstracta, un exterminio en masa, sin sujetos, mientras que la lucha del ejército alemán contra las "hordas rusas" aparece "dramatizada teatralmente" (ACHA, 1995, p. 115). Si en el frente oriental innúmeros individuos se excedieron a sí mismos ante la catástrofe, en los campos de exterminio se cuenta que las cámaras de gas eran el medio más efectivo de liquidación, es decir, prevalece un lenguaje burocrático ante la épica heroica del primero (HABERMAS, 1988b, p. 31). Hillgruber también recuerda el atentado contra Hitler del 20 de julio de 1944 sosteniendo que ello era fruto de una ética de la convicción, pero no de una ética de la responsabilidad. 
Si hubiese sido bien sucedido, el atentado comprometería la lucha contra el avance rojo. Otro argumento se refiere a cómo las leyes antisemitas de Nuremberg del año 1938 tenían "amplio respaldo" de la población ya que forzaban una "consciencia especial sobre los judíos" y consideraban que lo mejor para esa "cuestión" era la expatriación (HABERMAS, 1988b, p. 32). La identidad alemana que intenta forjar Hillgruber tiene, por lo tanto, una luz y una sombra bien destacadas. El frente oriental aparece como una superación patriótica mientras que el genocidio en los campos aparece "normalizado": sea por el lenguaje mismo de Hillgruber, sea por el desarrollo de los argumentos. "Normalizar" aquí se refiere a que las leyes de Nuremberg tenían apoyo popular y que el exterminio en los campos funcionaba según un procedimiento burocrático impersonal y masivo.

Fue Ernst Nolte quien elaboraró con comparaciones simplistas una relación aún "más patriótica" entre el frente oriental y el Holocausto. Una premisa necesaria era afirmar que la historia sobre el Tercer Reich había sido escrita predominantemente por los vencedores, lo que transformaría el período de la dictadura nazi en un "mito negativo" (HABERMAS, 1988b, p. 33). Un "revisionismo" entonces era necesario de parte de los historiadores alemanes. Su tesis buscaba rever la particularidad del horror nazi justificándolo con una interpretación "desde dentro" y comparando los campos de exterminio nazi con los campos soviéticos y con otras formas de exterminio masivo como el genocidio armenio por parte de los turcos. En 1987, Nolte publica La guerra civil europea (1917-1945), donde, entre otros argumentos, sostiene que sería posible reducir la complejidad de la Segunda Guerra en "una guerra civil" entre el bolchevismo y el nacionalsocialismo, pero que empieza no con la Primera Guerra, sino a partir de la Revolución Rusa (NOLTE, 1994, p. 15). Pensando en validar su argumento ante las posiciones ideológicas de la Guerra Fría, Nolte trata el período entre guerras como una guerra entre "Izquierda y Derecha": habría sido una guerra entre la Unión Soviética y las democracias burguesas de Europa occidental. Para Nolte, el fascismo se podría entender más como una reacción al comunismo que como una exacerbación de violencia e intolerancia de sectores con ideologías de derecha. De este modo, Nolte, además de encontrar una poco creíble justificación para la 
violencia fascista, relegaba a un claro segundo plano y hasta ocultaba la tendencia criminal del nacionalsocialismo, especialmente su racismo y antisemitismo (BALDWIN, 1990, p. 6).

Nolte estaba preocupado con la dialéctica entre las mutuas amenazas de aniquilación. Hitler tendría buenas razones para suponer que los rusos lo querían "aniquilar" (HABERMAS, 1988b, p. 33). Para Nolte, la revolución rusa habría sido una precondición del nacionalsocialismo y, por consecuencia, del holocausto. El despliegue de tropas alemanas a partir de 1944 en el frente oriental habría sido una reacción a la amenaza bolchevique. Esa "normalización” por medio de comparación era una premisa necesaria para construir una relación causal entre las atrocidades del bolchevismo y del nazismo. El frente oriental que combatía a los rusos en realidad quería evitar lo peor: que toda la burguesía de Europa fuese exterminada. Esa exageración era justificada por Nolte con una peculiar apropiación del concepto de trascendencia de Heidegger. Buscando una dimensión más "profunda”, hasta antropológica - "donde todos los gatos son pardos", ironiza Habermas - Nolte apunta a los impulsos antimodernos que cargarían una y otra reacción de las dos grandes ideologías que enfrentaban tanto occidente cuanto oriente. Marxismo y fascismo serían intentos de dar respuestas a las aterradores realidades de la modernidad (HABERMAS, 1988b, p. 35). El esfuerzo de Nolte está, por lo tanto, puesto en justificar el nazismo desde una confrontación entre ideologías políticas a posteriori. Si la historización de Martin Broszat recae en un anacronismo que ignora los efectos interpretativos posteriores al descubrimiento de Auschwitz, Nolte fuerza un simulacro de anacronismo al usar la Guerra Fría como una justificación de un supuesto posicionamiento ideológico correcto que las derechas fascistas habrían tenido ante "la amenaza soviética".

El argumento central de Nolte de que tanto la dictadura nazi cuanto el Holocausto serían una reacción a la amenaza bolchevique, le permite "deducir" otras arbitrariedades que simulan relaciones causales. Lá más importante se quizá que la simple anterioridad de los campos soviéticos de los años 1930 habría sido una "precondición" para los campos nazis, aunque no necesariamente una causa directa (BALDWIN, 1990, p. 9). Odio y persecución a los judíos sería para Nolte una "concretización" de la búsqueda de los enemigos de Alemania, 
una amenaza que habría sido propuesta por los bolcheviques. Si los bolcheviques persiguieron a la burguesía como clase, los nazis persiguieron a los judíos como raza. Así como Andreas Hillgruber, Nolte reduce la singularidad de la destrucción - del exterminio - de los judíos al "procedimiento técnico del envenenamiento por gas", y suelta su tesis de que en el archipiélago Gulag los bolcheviques habían sido más originales que en Auschwitz. Auschwitz se reduce así a un procedimiento (HABERMAS, 1988b, p. 35). Para construir ese punto de vista improbable e insólito, Nolte ofrece ejemplos de relatos dedicados a entender y afrontar el stalinismo. "Louis Fischer, por ejemplo, excomunista y experto en las condiciones soviéticas, escribe que las purgas de Stalin sólo tuvieron un rival en la historia: las cámaras de gas de Hitler"; Nikolai Tolstoi “[...] afirma que, en comparación con Stalin, Hitler fue casi un dechado de virtudes cívicas" (NOLTE, 1994, p. 25). Joachim Fest, editor del matutino conservador $F A Z$, apoyó el punto de vista de Nolte y se preguntó si la marca distintiva del nazismo, a saber, la muerte masiva industrializada, no habría sido utilizada por Stalin (FEST, 1991, p. 103). El 29 de agosto de 1987 Fest aún expresaría en el mismo periódico su insatisfacción con la insensibilidad de algunos académicos que "seleccionan sus víctimas” (HABERMAS, 1988a, p. 48). Para Nolte, el exterminio de los judíos durante la Segunda Guerra quedaría justificado, además de la "anterioridad de los campos soviéticos", por la cita que hace Nolte de Chaim Weizmann, en cuya declaración en el congreso mundial del Sionismo en septiembre de 1939 convoca a los judíos a luchar contra Alemania al lado de los ingleses (BALDWIN, 1990, p. 5). El golpe de efecto del argumento de Nolte, como señaló Habermas (1988b), está en la relativización del sentido moral del genocidio nazi. La justificativa directamente ligada a los judíos sionistas dejaría de parecer tan absurda y arbitraria. Todo eso porque, para Nolte, los historiadores alemanes tendrían no sólo que hacerse cargo de librar a Alemania de la carga moral de su pasado, sino también la función de aportar elementos para la construcción de la identidad del pueblo alemán actual, recrear una comunidad nacional a partir de un consenso narrativo "revisado" que le quitara "así a los alemanes la culpa" colectiva impuesta por las versiones históricas de los aliados después de los juicios de Nuremberg (ver ACHA, 1995, p. 114). 
Para Habermas los logros de las ciencias sociales e históricas no pueden ser reducidos a algunas pocas y puntuales demandas de "consciencia histórica" (HABERMAS, 1989a, p. 94). A medida que las ciencias problematizan la consciencia histórica, más aumentan los conflictos interpretativos y la necesidad de investigaciones y nuevas problemáticas. En el artículo publicado en 7 de noviembre en el diario Die Zeit intitulado Concerniendo el uso público de la historia, Habermas comenta que no se hubiera metido en la discusión si ésta se hubiera dado en periódicos especializados (1988a, p. 49). Habermas reconoce que la mera publicación del artículo de Nolte en el $F A Z$ no es un pecado, pero considera sin embargo que esa publicación marcó un punto de giro en la política cultural de la entonces República Federal de Alemania y que, además, fue llamativo desde el exterior, por eso consideró el filósofo necesario el debate. La relevancia para Habermas era contestar una estrategia "neoconservadora", como él denomina una convergencia de pensamiento e institucionalización política elitista y liberal, especialmente los partidos FDP, CDU y sectores de la SPD (ver HABERMAS, 1992), que buscaban forjar una identidad político-cultural alegando que, en caso contrario, "[...] las fuerzas de integración social podrían desaparecer [...]”, y que, por otro lado, "la pérdida de la historia" contra la cual autores como Nolte "luchan" podría acarrear en problemas de autolegitimación del sistema político de la República Federal ya que se estaría arriesgando tanto una autopercepción doméstica, es decir, "paz social”, cuanto una imagen desde el exterior, es decir, "confiabilidad en las relaciones internacionales” (HABERMAS, 1988a, p. 45). Estos argumentos conservadores parecieran justificar una provisión de significado (Sinnstiftung) compensatoria, es decir, una historización hecha a la medida de la identidad deseada desde cierto discurso político, o mejor, como el mismo Habermas identifica en el movimiento neoconservador, desde la "cultura política". Los neoconservadores de la República Federal de Alemania buscaban según Habermas las causas de la crisis no en los modos funcionales de la economía y de la administración del estado, sino en los "problemas condicionados culturalmente", sobre todo en la molesta relación entre democracia y cultura (HABERMAS, 1992, p. 79). En una manifestación de "antropología pesimista", los neoconservadores atacaban las bases del 
estado de bien estar social (ver OFFE, 1987) defendiendo el retorno de un "constitucionalismo alemán” que abría mano parcialmente de una forma democrática moderna y retomaba nebulosas premisas de un cierto "cristianismo de estado" (HABERMAS, 1992, p. 103).

La postura teórico-política de Habermas en la querella de los historiadores se sintetiza en su defensa del patriotismo constitucional [Verfassungspatriotismus]. Habermas acusaba al neohistoricismo conservador de aprovecharse de lo que Herbert Schnädelbach (1986) llamó neoaristotelismo según el cual "una práctica ni sería comprensible ni podría enjuiciarse si no es desde las formas de vida y tradiciones en que está inserta. Una práctica sólo podría justificarse desde su propio contexto" (HABERMAS, 1989b, p. 113). En contraposición a este relativismo situacionista que sin duda fue mal apropiado por los historiadores conservadores en su construcción artificial de una nueva consciencia histórica e identidad alemana, Habermas sostiene que la única forma válida de identidad sería un "patriotismo" necesariamente moderno y que defendiera la fundamentación del estado en los Derechos Humanos y la universalización democrática, es decir, la soberanía popular (HABERMAS, 1989b, p. 114). El argumento de Habermas se sostiene a partir de su propia interpretación de Max Weber en el marco de su recepción del giro lingüístico, es decir, en su teoría de la acción comunicativa (ver HABERMAS, 1981). La modernidad abre la posibilidad de cuestionar reflexivamente cualquier tradición, dogma o identidad. Los diversos procesos de la modernización "destruyen la 'naturalidad' de los aspectos clave del mundo de la vida” (SITTON, 2006, p. 143). En el estado moderno hay un desprendimiento reflexivo en relación a la metafísica y a la religión. Aunque el nacionalismo sea una superación de formas más tradicionales de identidad, sigue siendo sin embargo una atadura a la formación de prejuicios cuyo caso límite es la "movilización para una guerra por la patria” (HABERMAS, 1989a, p. 101). La identidad política postconvencional ya no se siente comprometida con "continuidades triunfales; es incompatible con una consciencia histórica que permanece ciega para la profunda ambivalencia de toda tradición” (HABERMAS, 1989a, p. 94). La formación identitaria postconvencional de los individuos sufre no sólo críticas a construcciones tradicionalistas, sino también reelaboraciones permanentes, 
adquisición de responsabilidades, incorporación de referencias éticas y jurídicas etc. El límite de esa posibilidad de crítica no es una postmodernidad ambigua, por un lado, reaccionaria ante la modernidad, y por otro, una aceleración y radicalización del desencantamiento del mundo, sino un universalismo moral que tiene como horizonte modos reflexivos de emancipación. El Verfassungspatriotismus representa para Habermas el hecho de "haber logrado superar duraderamente el fascismo, establecer un estado de derecho y anclar éste en una cultura que, pese a todo, es más o menos liberal" (HABERMAS, 1989 b, p. 116). Además, el patriotismo de la constitución permite que en última instancia la autoatribución de identidad colectiva sea en el marco del orden político y de los "principios constitucionales" (HABERMAS, 1989a, p. 94).

\section{El debate Goldhagen. Normalización por 'culturalismo'}

Si el debate en torno a la historización quedó restringido al ámbito académico y el Historikerstreit tuvo una repercusión muy bien situada en dos periódicos (además de revistas académicas especializadas), el debate Goldhagen empezó abalando la esfera pública con la publicación de millones de ejemplares de su muy bien escrito libro Hitler's willings Executioners. Ordinary Germans and the Holocaust (GOLDHAGEN, 1997). El libro fue traducido en diversos países antes de completado un año de la primera publicación en Estados Unidos, hasta reverberar en ámbitos de discusiones teórico-metodológicas que en coro y también con distintos argumentos reprochaban la demonización de los "alemanes corrientes" que proponía el libro. Ya a principio, la expresión del título del libro "ejecutores o verdugos voluntarios" pode en duda la conocida tesis de que los alemanes actuaron obligados en el marco de una dictadura. Si en la historización de Broszat la metodología parecía convertirse en mito para forzar una esquiva del horror o aún, el horror era agazapado en mito para liberar la metodología y poder profundizar de algún modo en conocimiento histórico pese a su evidente anacronismo interpretativo, con Goldhagen el mito de un monocausal antisemitismo que resucitaba a su modo la tesis del Sonderweg - o camino especial alemán - explicita una narrativa 
exagerada sobre el "voluntarismo asesino" de "los alemanes corrientes" - o "sociedad alemana en general" - durante el Tercer Reich. El mito se convierte en historia y se actualiza gracias al debate público y los modos argumentativos de los diversos contendientes académicos. La "espina clavada" (WEHLER, 1997a) que provocó en la esfera pública alemana el libro de Goldhagen sirvió no sólo para mostrar lo vivo que estaban los recuerdos en una memoria esforzada por reconciliarse, sino también para oxigenar el rechazo a la desmedida "culturalización" del planteo de Daniel Goldhagen así como otros modos de esencialización y relativización del Holocausto. En el caso de Goldhagen se evidenció un modo de normalización vía "esencialismo cultural", o aún, un modo unilateral y exagerado de la tesis intencionalista.

Al explicar cómo y por qué se produjo el Holocausto, Goldhagen se basa en tres estudios de caso: primero, sobre la participación de algunas unidades policiales en la matanza de judíos en Polonia; segundo, sobre los campos de trabajo para judíos; y tercero, sobre las marchas de la muerte llevadas a cabo tras el cierre de los campos de concentración. Sus preguntan eran: ¿hasta qué punto estaba enraizado el antisemitismo en la mentalidad de millones de alemanes? Cómo y en qué medida el antisemitismo hizo posible el tránsito desde la discriminación social, las vejaciones sociales, la persecución activa y los progroms hasta la "solución final"? Para eso, Goldhagen apuesta a un modelo interpretativo que se ocupa de las "visiones de mundo", el "carácter nacional", "las acciones" y "las opciones seguidas por los individuos". Su estrategia metodológica se basa en una necesaria relación entre la "responsabilidad" de esas acciones a una noción de "cultura política" (GOLDHAGEN, 1997, p. 12). Desde la Edad Media se ha mantenido entre "los alemanes" un antisemitismo surgido de la materialización del odio cristiano hacia el pueblo de los "asesinos de Cristo" (WEHLER, 1997a, p. 44). Para Goldhagen, es posible en un estudio de caso explicar históricamente "el carácter" y "la evolución" de lo que llama "cultura política" que, según aclara, no son inmutables, "no existe un 'carácter nacional' eterno". Tanto es así que el mismo Goldhagen afirma contradictoriamente que, en oposición a esos años terribles, "hoy en día la mayoría de los alemanes son verdaderos demócratas" (GOLDHAGEN, 1997, p. 13). Aunque advierta a principio que el Holocausto tiene muchas explicaciones posibles, 
Goldhagen explicita que su preocupación se centra en las "motivaciones": "la voluntad de matar a los judíos procedía principalmente, tanto en el caso de Hitler como en el de quienes llevaron a cabo sus planes asesinos, de una sola fuente común, a saber, un antisemitismo virulento" (GOLDHAGEN, 1997, p. 14). Tres factores fueron necesarios para el exterminio de seis millones de personas. El primero era el carácter estatal del antisemitismo; el segundo, las opiniones sobre los judíos en la sociedad eran compartidas ampliamente; y tercero, Alemania era el único país que tenía condiciones para hacerlo porque podía someter militarmente a todo el continente. Ni en Francia, ni en Polonia o Ucrania, por más antisemitas que hayan sido, hubo algo que se pareciera a un exterminio como el perpetrado por los nazis.

El punto central de la tesis de Goldhagen es el "antisemitismo eliminador" como política de estado que induce y organiza la persecución violenta y la matanza en diferentes niveles de una sociedad que desde mucho tiempo cultivaba un virulento odio hacia los judíos. No deja de ser notorio cómo el texto está impregnado de expresiones que refuerzan este presupuesto: "La oleada antisemita que había inundado a las universidades" (GOLDHAGEN, 1997, p. 118); "El antisemitismo era endémico en la Alemania de Weimar" (GOLDHAGEN, 1997, p. 119); "La letanía de la política y las medidas legales antijudías comenzó con ataques físicos instantáneos, pero todavía esporádicos, contra los judíos, sus propiedades, cementerios y locales religiosos, y con el establecimiento de campos de concentración 'desorganizados' tanto para ellos como para la izquierda política" (GOLDHAGEN, 1997, p. 127). "Los jueces y profesionales de la administración de justicia estaban tan deseosos de eliminar la influencia judía de sus instituciones y su país que, ya en los primeros meses del gobierno nazi, a menudo se adelantaban a los mandatos legales promulgados por el régimen” (GOLDHAGEN, 1997, p. 135). También Goldhagen se valió de muchas historias y relatos sobre individuos concretos:

Emma era 'judía' y estaba en una situación que podría haberse considerado apropiada como ninguna otra para que sus compatriotas alemanes la trataran con decencia. Casada con un católico, se había convertido a la fe de su marido, renunciando así a su identidad judía y cortando sus lazos 
formales con el judaísmo. Sin embargo, en 1940, sus vecinos dejaron bien claro que no deseaban vivir cerca de ella, pues, desde su punto de vista racial, era evidente que seguía siendo judía (GOLDHAGEN, 1997, p. 143).

Con esos y muchos otros ejemplos Goldhagen quiere mostrar que había de hecho ya desde antes mismo de la asunción de Hitler una "cuestión judía" que se acentuara aún más, como "cultura política", cuando desde el estado se oficializó una política racial antisemita. Sin embargo, a partir del avance en los análisis de los datos, no se puede negar que la narrativa de Goldhagen convoca a un cierto morbo y sensacionalismo con un énfasis simplificador sobre el antisemitismo. En su análisis de los diversos contextos de la recepción del libro de Goldhagen, Federico Finchelstein comenta la obsesión y fascinación del autor con detalles de crueldad y horror que parecían escenificar el salvaje maniqueísmo entre el "placer de los perpetradores" y el sufrimiento de las víctimas (FINCHELSTEIN, 1999, p. 56). Anson Rabinbach (1997) llamó la atención a la incapacidad de Goldhagen en "[...] matizar la repetición compulsiva de elementos del pasado [...]", invocando el pasaje del libro que cuenta cómo bebés eran fusilados:

[D] ecidieron entrar en un hospital, un centro sanitario, y disparar contra los enfermos, los cuales debieron encogerse de miedo, rogar y pedir misericordia a gritos. Mataron bebés. Ninguno de los alemanes ha considerado oportuno contar detalles de tales matanzas. Con toda probabilidad, un asesino o bien mataba a un bebé en brazos de madre, y quizás a ésta por añadidura, o bien, sujetaba al niño por la pierna, con el brazo extendido, y le disparaba con una pistola. Tal vez la madre contemplaba la escena horrorizada. Entonces arrojaba al minúsculo cadáver como si fuese basura y lo abandonaba para que se pudriera (GOLDHAGEN, 1997, p. 278).

El estatus “ontológico” o deliberadamente "étnico" que le atribuye Goldhagen al antisemitismo suena como una contradicción performativa cuando, a la vez, afirma que se está refiriendo a la conducta responsable de individuos. Al mismo tiempo que los "justifica” les 
echa la culpa. Esa contradicción fue señalada por A. D. Moses (1998) al explicar que Goldhagen intenta conciliar la "narrativa particularista" con la "narrativa universalista”. En su búsqueda por mostrar la agencia individual, Goldhagen no logra desenredarse de una confusión entre behavorismo y antropología cultural (MOSES, 1998, p. 217). Al determinar el unilateral comportamiento de los alemanes antisemitas, no se considera ningún otro aspecto cultural que pudiese poner a prueba o al menos matizar la caricatura del "alemán antisemita". Además, con esa estrategia argumentativa se confunde la claridad con la simplificación, hasta el punto que se "argumenta más como fiscal que como historiador” (ULRICH, 1997, p. 12). Habermas también hace hincapié en que, para el historiador, la imputabilidad de las acciones no decide sobre su culpa o su inocencia, sino sobre el tipo de los motivos explicativos (HABERMAS, 2001, p. 42). La explicación causal no es suficiente ni para imputar y ni para exculpar a los actores de determinada acción. Las imputaciones explicativas del historiador marcan un nivel ético-político distinto en relación al discurso jurídico o moral, aunque muchas veces el trabajo del historiador haya servido como elemento en los juicios a los nazis y vice-versa, cuando actas y fallos de juicios sirven de base documental al trabajo del historiador.

Christopher Browning ha trabajado a partir de actas y archivos judiciales el "punto de vista del perpetrador común" (2007, p. 52), por así decirlo. Dedicó su investigación a la acción de exterminio en la aldea polaca de Jozefow perpetrada por el Batallón Policial de Reserva 101, compuesto por aproximadamente 450 hombres de media edad que tenían ya familia y eran en su mayoría provenientes de Hamburgo, pero también de otros países como Luxemburgo. Hans-Ulrich Wehler recuerda que no sólo "alemanes de origen" participaron en los fusilamientos de judíos, sino también "voluntarios de las SS de los países europeos ocupados" como letones, lituanos, ucranianos y rumanos (WEHLER, 1997a, p. 48). ¿No le faltaría a Goldhagen una perspectiva comparativa dada la complejidad del Holocausto en vez de totalizar su recorte en torno a un sólo aspecto de los alemanes, tornando la causalidad del Holocausto "un problema étnico"? Browning menciona que el mayor Wilhelm Trapp, que comandaba esa compañía, lloró todo el día como un niño. Muchos de los hombres se resistieron o afirmaron tratarse de una tarea asquerosa y así "[...] 
los liberaban del pelotón de funcionamiento y los reasignaban como escolta de los camiones" (BROWNING, 2007, p. 49). En su investigación a partir de 125 testimonios oriundos de una investigación penal realizada en el estado alemán de Niedersachsen, Browning, a pesar de conocer los peligros de una "normalización" de trabajos como el suyo, no ve serias objeciones a trabajar con la así llamada Alltagsgeschichte, defendiendo que no hay nada en ella "[...] que necesariamente atenúe la posición central del Holocausto en la historia de la Alemania nazi" (BROWNING, 2007, p. 65). Trata de reconstruir, así, el día de la masacre de Jozefow. Analizando los testimonios le llamó la atención que una buena parte de los alemanes, "tres de trece", encararon la tarea de modo absolutamente contrariado y "[...] se mantuvieron absolutamente al margen de todas las acciones contra los judíos" (BROWNING, 1997, p. 16), lo que refuta o al menos relativiza el antisemitismo ontológico de Goldhagen. En el estudio de Browning está también la referencia a "asesinos despiadados y sádicos" como Karl Schutz, que "disparaba entusiasmado" (BROWNING, 1999, p. 119). "Comprender" no significa necesariamente aceptar o entender el hecho como "justificable". Goldhagen, a diferencia de Browning, no habla de los voluntarios de otros países que colaboraron en las masacres, lo que haría dudar de su obstinación con el antisemitismo alemán (LACAPRA, 2005, p. 140).

Browning quiere entender cómo se dio lo más concretamente posible la masacre de Jozefow, cómo opera el negacionismo a partir del discurso y cómo los testimonios recrean situaciones de modo sesgado, y de ningún modo generar una "comprensión empática" que permita ponerse en lugar de los policías del Batallón y menos aún eventualmente perdonarlos según las intenciones que relatan haber tenido. Goldhagen se refiere al Batallón 101 e inclusive al mayor Trapp pero en una acción en el pueblo polaco de Talcyn en septiembre de 1942. Aquí aparece una diferencia considerable entre ambos autores: Goldhagen afirma que los alemanes estaban reticentes de matar a polacos pero "[...] saciaron su sed de sangre judía" (GOLDHAGEN, 1997, p. 240), siendo que en el relato de Browning aparece que los alemanes asesinaban a polacos partisanos de modo más cruel y "justificado", y que matar a judíos resultaba una tarea "sucia" e inmoral, salvo para algunos oficiales sádicos, que sí los había. Goldhagen, que a su modo también se vale de la Alltagsgeschichte, 
omite relatos y testimonios arbitrariamente para "demostrar" su tesis del antisemitismo ontológico y eliminacionista. Ruth Betina Birn, que debido a sus críticas fue demandada judicialmente por Goldhagen, conoció al célebre autor en una estadía de investigación en el archivo de Ludwigsburg donde éste tuvo acceso al mismo material, y escribió cómo el autor tergiversó las fuentes de modo a mostrar su tesis definida de antemano: encontrar y culpar a "alemanes totalmente corrientes" (BIRN, 1997). Sobre la retórica ficciosa de Goldhagen, Dominick LaCapra (2005, p. 135) comenta que ésta se vale de una mezcla del estilo indirecto libre, citas textuales, enfoque tendencioso de víctimas estereotipadas como "las niñitas" y especulaciones o proyecciones sobre sentimientos que aparentemente atribuye a los perpetradores en un proceso que exige del lector una identificación empática con la "mentalidad" del asesino. Pero paradójicamente, en su escritura casi literaria que visa atrapar el lector mediante el morbo y la curiosidad, Goldhagen también presupone una identificación con las víctimas aunque su énfasis narrativa esté puesta en el punto de vista del perpetrador. Para LaCapra, "Goldhagen alude confusamente al trauma del perpetrador sin formular explícitamente el problema ni abordarlo en términos convincentes y diferenciados" (2005, p. 136), pero no hace más que imaginar qué piensan esos perpetradores a través de su propia imaginación de escritor poniéndose en lugar de algunas víctimas. Lo inadecuado del abordaje de Goldhagen es la cuestión en torno a la excesiva victimización, donde los victimarios son demonizados unilateralmente y las situaciones son sólo ejemplos puntuales de algo generalizado. Si Browning habla de "[...] hombres comunes e implícitamente dice que cualquiera en una situación particular puede tener motivaciones fuertes para comportarse de manera determinada”, Goldhagen se limita a categorías socio-psicológicas de "los alemanes" y "argumenta que no es necesaria ninguna explicación sobre las desviaciones de una presunta normalidad en razón del larguísimo condicionamiento que implicaba el antisemitismo eliminacionista alemán” (LACAPRA, 2005, p. 140).

Es innegable la participación de numerosos alemanes comunes en los asesinatos en masa de judíos y que esas ejecuciones hayan presentado alto "grado de voluntarismo" (BROWNING, 1999, p. 115). Sin embargo, para Goldhagen, el antisemitismo eliminacionista tiene 
un origen bastante anterior al nazismo, aproximadamente dos siglos, argumento que recae en una anacrónica reconstrucción "culturalista" del Sonderweg. El argumento de Goldhagen representa un notable retroceso sobre "los orígenes" del nazismo en términos de posibles continuidades con la historia anterior de Alemania, especialmente el imperio. La polémica en torno a las tesis del Sonderweg se restringía a las transformaciones políticas de Alemania desde su unificación del siglo XIX pero que consagraron una ausencia notable de democracia en términos formales en favor, primero, de una monarquía constitucional y, luego, de un parlamentarismo. Hans-Ulrich Wehler sostiene que el período entre $1871 ; 1945$ es caracterizado por una fuerte modernización económica, pero con fuerte concentración de riqueza y poder, lo que conllevó a un gran retraso político en términos de democratización si comparada a países como Estados Unidos, Inglaterra y Francia (ver WEHLER, 1981 y 1997b). Pese a idealizar las formaciones políticas de esos países como si con sólo haber una cultura política liberal hubiera una democracia estable, Wehler aporta una innegable complejización a partir de una historia política. Como explica Finchelstein, "la cultura política del imperio estaba dominada por la autoritaria aristocracia prusiana que intentaba detener de cualquier forma la democratización” (2010, p. 82). Sin embargo, la explicación por "la falta de modernización plena" no debe servir como pretexto para relativizar un desarrollo histórico que presupone un necesario continuismo entre el imperio alemán y el nazismo, como lo sostienen los historiadores conservadores Andreas Hillgruber y Klaus Hildebrand (FINCHELSTEIN, 2010, p. 87). Sin duda son innegables los elementos autoritarios y los débiles arraigos a un estado legalmente constitucional, pero que se pueda reconocer uno y otro aspecto de continuidad no debe permitir explicar o quizá justificar el desborde de violencia del nazismo como una "característica cultural". Uno de esos aspectos, tal vez el más llamativo, no se refiere al antisemitismo omnipresente, como quiere Goldhagen, sino a la demagogia de los emperadores y su influencia sobre las masas y movimientos políticos organizados de derecha, lo que promovió una progresiva politización de las clases subordinadas en el contexto más amplio de la 0 alemana, pero "[...] que claramente no implicaba una democratización en términos parlamentarios” (FINCHELSTEIN, 2010, p. 91). 
Más allá de las diversas continuidades político-culturales que pudo haber tenido el imperio alemán con el nazismo, no es posible aceptar una justificación de orden "cultural", como propone de forma contradictoria Goldhagen: si, por un lado, el autor culpa a "alemanes corrientes" por un aspecto de "su cultura política", por otro, los inculpa porque esa misma cultura serviría de justificación, es decir, atenúa tanto el problema moral como las implicaciones de responsabilidad política específicas e implícitas en el hecho criminal. Es preciso considerar que hubo "previamente una segregación social de los grupos perseguidos", y que la Solución Final de la "cuestión judía" se dio ya en el contexto de la guerra y de una dictadura (MOMMESON, 1999, p. 108). Desde el punto de vista de Goldhagen, Hitler aparecería como una consecuencia necesaria de la historia alemana, cuyo antisemitismo se consolidó desde fines de la Edad Media. Eso hace que Goldhagen deje de lado a todos los factores situacionales en favor de una única explicación, como si únicamente judíos hubiesen sido asesinados por sádicos "que mataban por placer" (GOLDHAGEN, 1997, p. 185). Como afirma Bankier, "los alemanes comunes sabían cómo distinguir entre discriminación aceptable [...] y el horror inaceptable del genocidio [...] Cuanto más se filtraban las noticias de la matanza en masa, menos el público quería estar involucrado en la Solución Final de la cuestión judía" (BANKIER, 1992, p. 151 apud BROWNING, 1999, p. 120). Para Mommsen, Goldhagen se sitúa en el ala más extrema de la historiografía intencionalista al sostener que Hitler siempre tuvo en mente llevar a cabo un ineludible exterminio de los judíos especialmente cuando la situación de dominio en Europa se lo permitía. Sin embargo, la mayoría de los investigadores sostiene que "hasta 1940 el régimen no contemplaba otra solución que la deportación de los judíos" (MOMMESON, 1999, p. 113).

Como explica en el prefacio a la edición alemana ya conociendo a algunos de sus críticos, Goldhagen no quiere, sin embargo, recaer en la tesis de la "culpa colectiva", en el sentido de Karl Jaspers, como si absolutamente todos los alemanes por solo pertenecer a una colectividad hayan sido culpables por añadidura. Según Götz Aly (1998), uno de los especialistas más reconocidos y defensor de la tesis "estructuralista", Goldhagen parece obstinado en radicalizar la tesis "intencionalista" y deja de lado los elementos estructurales que 
escapaban al control subjetivo de "[...] los alemanes corrientes" que busca a toda costa incriminar. Para Goldhagen, "[...] los alemanes individuales no fueron piezas de un mecanismo, autómatas, sino participantes responsables capaces de elegir y, en última instancia, autores de sus propias acciones" (1997, p. 18). Antes que un exclusivo "modelo cognitivo" unilateral, lo que propone Browning es tener en cuenta también otros factores ideológicos y situacionales en el contexto de un régimen dictatorial. Goldhagen, al sostener que "la revolución nazi fue consensuada" (GOLDHAGEN, 1997, p. 560), parece ignorar que una dictadura no es un régimen consensual, que las ideologías extremas se propagan por una máquina de propaganda, restricciones a la libertad, "una epidemia de hipocresía en todo discurso público y la corrupción de la sinceridad en el comportamiento público" (BROWNING, 1999, p. 131). El antisemitismo hace parte de esas ideologías y es, así, condición necesaria pero no suficiente para explicar el recurso a la Solución Final. Una tesis contraria al intencionalismo culturalista de Goldhagen es la tesis del "proceso acumulativo de radicalización" sostenida por Hans Mommsen. La estructura del régimen nazi remitía a instituciones que estaban sometidas a una dura y larga competitividad que llevó, no sólo a una "selección negativa de intereses políticos", sino también a un proceso acumulativo de radicalización que desembocó en la liquidación de los judíos. Por eso Mommsen argumenta que el elemento burocrático en la construcción colectiva del genocidio "[...] es al menos tan relevante como el odio a los judíos que se agudizó como mecanismo compensatorio en el núcleo de las élites del nacionalsocialismo" (MOMMSEN, 1999, p. 107). Para Breton y Wintrobe (1986), los burócratas como Adolf Eichmann se hallaban en una estructura competitiva en la que eran premiados por iniciativas empresariales que promovían los intereses y los objetivos de sus superiores. Según cuenta Mommsen, el auténtico impulso para el Holocausto partió de un grupo de antisemitas fanáticos que eran minoría, pero que eran animados por el propio Hitler y empujados por ese reconocimiento:

Muchos de los principales ejecutores como Adolf Eichmann o Theodor Dannecker no se convirtieron en antisemitas despiadados y fanáticos hasta que iniciaron su ascenso en el seno de las SS, ascenso que les permitió superar determinadas 
situaciones profesionales adversas de su vida civil y, desde luego, no actuaron así en absoluto sólo por razones estrictamente ideológicas (MOMMSEN, 1999, p. 106).

Más allá de diversos tipos de recepción y rechazo que pudo haber tenido el trabajo de Goldhagen en la esfera pública, quisiera destacar a dos que trascendieron el ambiente académico. El primero es Norman Finkelstein que vincula el trabajo de Goldhagen a una versión sionista-estadounidense del Holocausto (FINKELSTEIN, 1997). Conocido por su militancia contra el sionismo y todo lo que concierne a la "industria del Holocausto" (ver FINKELSTEIN, 2014), el autor salió en muchos medios de comunicación a reprochar el trabajo de Goldhagen desde un trasfondo político y metodológico, alegando que éste buscaba victimizar a los judíos exagerando al antisemitismo para de alguna manera contrarrestar en la opinión pública la guerra de los seis días y la brutal avanzada de Israel contra los territorios palestinos. La revista alemana Der Spiegel publicó dos notas distintas en dos números consecutivos, el 33 y el 34, ambos de 1997, donde se presentan las críticas de Finkelstein a Goldhagen. Si Goldhagen buscó legitimación en la condición de su padre como víctima del Holocausto, Finkelstein por su parte también: sus padres sobrevivieron tanto al guetto de Varsovia como a Auschwitz. Contra la tesis ultraintencionalista defendida por Goldhagen, Finkelstein retoma un texto del cronista de Hitler:

Aún en la guerra, cuando la maquinaria de exterminio ya se hallaba a pleno, él consideraba la masacre de judíos sólo como forma de una amenaza de política externa. Él sabía muy bien que semejante programa de exterminio sería rechazado por la masa del pueblo y por la mayoría de los compañeros de partido" (GOLDHAGEN..., 1997, p. 157).

Después de la guerra, Alemania fue ocupada y reconstruida visando un estado democrático, los culpables fueron juzgados en Nuremberg y otros juicios locales e internacionales, la población fue "desnazificada" [entnazifiziert] y, finalmente, ya en 1996, Goldhagen pudo ser recibido en el nuevo país reunificado, especialmente en 
medios de comunicación como los canales ZDFy Eins, para hablar de su obra y, claro, para promocionarla, no sin recibir durísimas críticas con aplausos del público incluidos. Finchelstein comenta que en su gira promocional, "Goldhagen fue tratado por el público y los medios como una controvertida estrella del espectáculo" (1999, p. 64) que venía a marcar un quiebre en la autopercepción de los alemanes sobre el Holocausto y su consciencia democrática actual. Venía a hablarle a los hijos y nietos de los perpetradores que nacieron después de la guerra. Su misión parecía consistir en extenderle a los alemanes un "[...] certificado de buena salud democrática [...] explicándoles las diferencias entre su oscuro pasado y su luminoso presente" (FINCHELSTEIN, 1999, p. 64). El "Premio Democracia" que recibió Goldhagen en marzo de 1997 en Alemania no escondió su "carácter performativo" dada la resonancia que tanto el libro como el autor tuvieron en Alemania (HABERMAS, 2001, p. 38). La exposición amplia, pero al mismo tiempo niveladora de hechos tan complejos, pareció satisfacer la necesidad de explicaciones simplistas de la masa del público. Habermas no ve como justificado el amplio y categórico rechazo que tuvo el libro de Goldhagen por parte de los historiadores académicos, aunque no deje de ironizar y distanciarse apuntando que el libro por su estilo de una estética de la crueldad obtiene efectos emocionales "[...] con descripciones obscenas que oscurecen la facultad de juzgar” (HABERMAS, 2001, p. 38). Habermas valora la incidencia positiva que tiene un libro de origen académico con estatus de bestseller sobre el pasado reciente que aborda un tema tabú como es el Holocausto y, además, rescata en defensa de Goldhagen el argumento de Herbert Jäger (1997) de que el polémico libro no afirma una culpa colectiva, sino que nos presenta una culpa individual en masa. Habermas sabe, sin embargo, que el libro contiene errores metodológicos como la tesis ultraintensionalista de "un camino derecho hacia Auschwitz" con muchos ejemplos y descripciones seleccionadas casi siempre descontextualizadas para sostener su golpe de efecto aterrador (HABERMAS, 2001, p. 48). Pero ese y otros errores no invalidan la importancia de abrir un debate y discutir el pasado, especialmente después de la unificación que, ya desde el primer Historikerstreit, dejaba en evidencia los problemas que implican forjar una identidad a partir de una consciencia histórica superadora del pasado nazi. 


\section{Consideraciones finales:̨ Debatir para aprender con la historia? La historia como crítica permanente}

En una etapa ya posterior al Historikerstreit, el historiador conservador Michael Stürmer se pregunta en un breve artículo en el $F A Z$ del 27 de diciembre de 1993 "[...] durante cuánto tiempo hemos de seguir permitiendo todavía al convidado de piedra del pasado ejercer su derecho a veto sobre todo el presente y sobre todo el pasado en cuestiones de virtud ciudadana y amor a la patria”. En un corto texto de 1994 publicado en su Kleine politische Schriften VIII, Habermas escribe, en respuesta a Michael Stürmer, que

para aprender de la historia no podemos echar a un lado ni reprimir los problemas no resueltos; tenemos que mantenernos abiertos a las experiencias críticas; pues de otro modo ni siquiera podemos percibir los acaecimientos históricos como desmentidos, como evidencias del fracaso de nuestras expectativas (HABERMAS, 1997a, p. 47).

Está en juego "[..] la idea de que sólo podemos aprender de la historia cuando la consideramos una instancia crítica" (HABERMAS, 1997b, p. 73). Retomando un texto de Reinhart Koselleck, Habermas afirma que la historia como magistra vitae conduce al engaño si tenida en cuenta sólo como lectura afirmativa. Una historia magistra vitae crítica nos dice sobre todo "[...] qué ruta no podemos emprender" (HABERMAS, 1997b, p. 47). Habermas, intelectual referente del SPD (Partido de la Socialdemocracia Alemana), se refería, además del mencionado artículo de Stürmer, al contexto alemán, específicamente a cómo la CDU (Unión Democrática Cristiana) se consolidaba políticamente con discursos xenófobos y elitistas, como en Baviera. "Y quien se pone a despedir a tal instancia misma calificándola de 'convidado de piedra del pasado [...]", concluye Habermas, "[...] lo único que demuestra es que no quiere aprender nada de la historia" (HABERMAS, 1997b, p. 47). Sin embargo, una lectura atenta de Koselleck nos permitiría tal vez desarrollar la lectura de Habermas que, en la brevedad de su texto, considera el 
topos de la historia magistra vitae de modo parcial y busca un claro efecto performativo, dado el contexto del debate.

Los tres debates recién presentados podrían ser sintetizados y reescritos a partir del par de categorías metahistóricas propuesto por Reinhart Koselleck: espacio de experiencia y horizonte de expectativas. Para Koselleck, ambas categorías son claves para abordar la temporalidad en la historia. Pasado y futuro no coinciden nunca, lo que permite concluir que

\footnotetext{
“[...] una expectativa jamás puede ser deducida totalmente de la experiencia. Una experiencia, una vez hecha, está completa en la medida en que sus causas son pasadas, al paso que la experiencia futura, anticipada como expectativa, se descompone en una infinidad de momentos temporales" (KOSELLECK, 2006, p. 310).
}

La presencia del pasado como experiencia debe ser distinguida de la presencia del futuro, de la expectativa. Lo que se espera para el futuro está claramente limitado de una forma diferente de lo que fue experimentado en el pasado. Las expectativas, como los pronósticos y previsiones, pueden ser revistas, mientras que las experiencias hechas son reunidas. Sin embargo, es únicamente en la historia que esas categorías pueden articularse. En la Edad Media, donde predominaban la Iglesia y las profecías escatológicas, el espacio de experiencia y el horizonte de expectativas prácticamente coincidían: los pronósticos eran deducidos mayormente de eventos pasados y estaban impregnados con la ideología bíblica oficial. Una profecía no realizada podía ser reiterada. "La estructura repetitiva de la expectativa apocalíptica garantizaba que las experiencias contrarias, aquí abajo, fueran inmunizadas" (KOSELLECK, 2006, p. 316).

Sin embargo, a partir del Renacimiento y de la Reforma, los progresos técnicos y los logros propiamente políticos para lograr la paz en el campo de la religión en razón de la guerra de los 30 años consolidó una nueva calidad de expectativas hacia el futuro. El horizonte de expectativas empieza a desacoplarse del espacio de experiencia de un nuevo modo. Si antes la retomada de una profecía del fin del mundo quedaba incrustada en el ciclo natural de varias generaciones, después 
del descubrimiento del muevo mundo y del consecuente descubrimiento de otros pueblos, y a partir de la revolución copernicana y la consolidación de la ciencia, se transforma la relación entre espacio de experiencia y horizonte de expectativa: surge una noción de "progreso" (social, económico y técnico) que permite proyectar una aceleración de la percepción del tiempo. Si antes los pronósticos estaban sometidos a la colección de eventos del pasado, a partir del siglo XVIII esas previsiones se transforman en expectativas de largo plazo "para un futuro nuevo" (KOSELLECK, 2006, p. 319). El progreso no podía ya depender sólo de la experiencia: algo ineludiblemente nuevo se proyectaba en el horizonte de expectativas. La Revolución Francesa no sólo reconfiguraba toda expectativa política, sino que además mostraba la intensidad de los cambios que en el futuro podrían darse: parecía que no era "[..] más posible proyectar ninguna expectativa a partir de la experiencia pasada" (KOSELLECK, 2006, p. 319). Aunque no pudiera ser deducido de la experiencia, el futuro trajo la certeza de que las invenciones y avances científicos podrían crear un mundo nuevo. Se creaba así una irreversible asimetría entre el espacio de experiencia y el horizonte de expectativa. Ciencia y técnica de cierto modo "[...] estabilizaron el progreso como siendo la diferencia temporal progresiva entre la experiencia y la expectativa” (KOSELLECK, 2006, p. 321). Así, para Koselleck, "[...] en la modernidad la diferencia entre experiencia y expectativa no para de crecer" (2006, p. 322).

La historia como ciencia tuvo que incorporar esa asimetría a su concepto, y para eso dejó de orientarse por experiencias pasadas individualizadas y organizadas cronológicamente para pasar a ser considerada una totalidad: una "totalidad abierta para un futuro portador de progreso" (KOSELLECK, 2006, p. 319). La historia se condensó en un término "singular colectivo" y pasó entonces a ser "sujeto y objeto de sí misma" (KOSELLECK, 2013a, p. 54). La "historia misma” como algo único viene a ser "un desenlace del Historicismo" (KOSELLECK, 2013a, p. 53). Si toda la historia es única, también el futuro debe ser único, distinto, por supuesto, al pasado. La historia tiene una unicidad continua: ya "[...] no podía ser enseñada como ejemplo" (KOSELLECK, 2006, p. 319). Sin embargo, las categorías de aceleración y retraso, evidentes desde la Revolución francesa, modifican en ritmo variable las relaciones entre pasado y futuro en razón del partido o punto de 
vista político (KOSELLECK, 2006, p. 59). La historia ya no puede ser la "maestra" [historia magistra vitae] que nos provee un arte político-terapéutico. La historia sólo puede ser "instructiva" en la medida en que "puede conducir y entusiasmar los ánimos en dirección a una recreación autónoma e independiente" (KOSELLECK, 2006, p. 60). En la conformación de la historia como una unidad reside la distinción entre Historie y Geschichte. La primera, vinculada a la idea de magistra vitae, servía no sólo de instrucción por su pretensión de determinar el espacio de experiencia a través de la ostensiva colección de hechos históricos pasados, sino también para sentenciar y juzgar acontecimientos históricos, es decir, someter a la experiencia pasada el horizonte de expectativas. Es lo que pretende Habermas en su respuesta a Michael Stürmer: usar cierto sentido político de la historia reciente como advertencia. Tal uso, diría Koselleck, presupone algo como "una justicia inmanente a la historia" (2006, p. 56).

La segunda [Geschichte] hace referencia a una "justaposición de camadas" [Schichtung] (KOSELLECK, 2006, p. 135). La metáfora es espacial y tiende a una imagen de algo estático. Es de ésta metáfora que podemos pensar la historia como un modo de conocimiento que busca la estructura, lo abstracto presente en los eventos y coyunturas. La historia como ciencia permite pasar críticamente de un orden de duración a otro, comparar, distinguir, resaltar la especificidad, pero también aproximaciones respetando el nivel de abstracción que las justifica. Es lo que nos permite advertir sobre la tesis arbitraria y ultraintencionalista de Goldhagen: nos abre la necesidad de recurrir a distintos niveles de argumentación. Nos lleva a complejizar los argumentos para entender de algún modo siempre parcial el fenómeno del nacionalsocialismo: por un lado, los eventos como las masacres del 101 Batallón de Policía o las marchas de la muerte e incluso la receptividad de un libro como Los verdugos voluntarios de Hitler en Alemania. Por otro, aspectos estructurales como el antisemitismo, la radicalización ideológica del régimen, la sistematicidad del exterminio en los campos, las memorias de las víctimas, las tesis sobre el Sonderweg etc. Una no clara distinción entre el nivel de los eventos y el de las estructuras fue el gran error de Goldhagen. Para el autor estadounidense, un evento se podría explicar simplemente por una asociación directa a algún aspecto estructural, como el antisemitismo. Eso lo llevó a una 
reconstrucción anacrónica en términos de justificación metodológica de la tesis del Sonderweg, "[...] el camino derecho hacia Auschwitz", como ironizó Habermas. Koselleck le advertiría a Goldhagen que "[...] cada contexto de fundamentación posee potencialmente una multiplicidad tan grande como la suma imaginada de todos los posibles acontecimientos y sus conexiones con el pasado" (2006, p. 262). Apostar tan solo por un aspecto, como el "antisemitismo eliminador", es "crear una ciega necesidad que nunca puede probar porqué algo ocurrió de esta y no de aquella manera" (KOSELLECK, 2006, p. 265). Nos interesó aquí mostrar el contexto de la recepción. Por un lado, los historiadores alemanes pudieron movilizar poco más de cincuenta ańos de estudios sobre el período nacionalsocialista para refutar a Goldhagen. Es decir, el espacio de experiencia que recibe al libro Los verdugos voluntarios de Hitler disponía de un diversificado nivel de reflexividad: muchos trabajos de investigación y líneas teóricas que complejizaron el período estudiado de tal manera que una tesis "monocausal" jamás podría hacerle justicia a esa diversidad. El horizonte de expectativa, más allá de los permanentes avances sobre la complejidad de los estudios sobre el Tercer Reich, era el de una nueva democracia, que venía de una festejada reunificación. El "premio democracia” dado a Goldhagen en 1997 es, en su performatividad, un autopremio por la tolerancia y la capacidad de autocrítica.

Desde el punto de vista de la historia de los conceptos, explica Koselleck, "Historie y Geschichte se contaminaron mutuamente, pero con un claro predominio del término Geschichte en el doble sentido de ciencia y narración, por un lado, y de entramado de acontecimientos y efectos, por otro" (KOSELLECK, 2013a, p. 52). A partir de 1770, ya en el contexto del idealismo, el término historia asume un valor trascendental. "La historia se convirtió en una categoría subjetiva de la consciencia, en forma análoga, por lo demás, a los conceptos 'revolución' y 'progreso'” (KOSELLECK, 2013a, p. 52). La historia, entendida como colectivo singular, además de haberse vuelto una categoría subjetiva de la consciencia, encierra también "la condición de posibilidad de todas las historias individuales" (KOSELLECK, 2013a, p. 55). La historia en si misma pasa a ser un concepto que aspira a la totalidad: desde la Revolución Francesa "historia" se convierte en un concepto "metahistórico". Sin embargo, el uso del concepto 
historia como una categoría trascendental pasó por distorsiones, por así decirlo, más allá del campo histórico-filosófico. Koselleck usa el término "acrítico" para referirse a apropiaciones secularizadas: "[...] la historia universal es el tribunal universal; la historia se torna omnipotente, omnisciente e infinitamente justa [...]"; es como si pasase a ser, para algunos, "la religión de nuestro tiempo", escribe en 1876 Klaus Lankheit (KOSELLECK, 2013a, p. 56). En la política, se convoca la historia como verdad para exhibir y justificar a la vez las intenciones, como en el discurso de Hitler: "Seremos recordados por nuestra obra en la más lejana posteridad” (KOSELLECK, 2013a, p. 57). La historia como término que remite a lo "colectivo singular" puede ser maleable y estar sujeto a usos performativos, recurrir a "valores". Koselleck defiende entonces que la ciencia histórica siempre va a buscar su unicidad como recurso crítico-metodológico. Cuanto más problemática se vuelve la "historia en sí", "la historia sin más", tanto más legítima y necesaria "se vuelve la investigación histórica como ciencia crítica” (2013a, p. 59).

Como instancia crítica permanente, la historia construye a partir de su temporalidad presente específica su relación con el pasado y el futuro. La necesidad inmanente de un presente debe poner en movimiento las pretensiones semánticas de larga duración y evento. Koselleck le atribuye una forma antinómica cuando dice que "[...] el pasado es absolutamente pasado, es irrevocable - y al mismo tiempo no lo es: el pasado es presente y contiene futuro" (2013a, p. 68). Es como si la pretensión trascendental de la historia se fugara en el instante mismo de su escritura, de su presente. "La diferencia entre la historia real y la historia interpretada se reproduce de nuevo en forma permanente" (KOSELLECK, 2013a, p. 102). Esto conlleva a que Koselleck defienda una metodología de la historia que pueda abarcar como objeto las historias, en plural. No sería posible atar semánticamente la pluralidad de historias (épocas, estructuras, distintas interpretaciones y narraciones de eventos etc.) a un concepto trascendental de historia, como en el idealismo alemán. Las perspectivas de los historiadores permanecen vinculadas al lugar en que están posicionadas, al contexto en que fueron concebidas. El tiempo del historiador debe ser un dato metodológico inmanente: es la presentificación que tiene la historia, la garantía de que será pasado en una venidera perspectiva del futuro. "La forma de la historia en general, y con ello la de las historias que 
han de poder hacerse visibles por medio de ella, es [paradójicamente] su temporalidad específica” (KOSELLECK, 2013a, p. 78).

Volvamos a Habermas y al par conceptual espacio de experiencia $y$ horizonte de expectativa. Como pudimos ver en los debates, Auschwitz impone que se tenga en cuenta el espacio de experiencia para advertir sobre cierto horizonte de expectativa. El futuro pareciera estar asombrado por las huellas del Holocausto. La memoria de la tragedia invierte el "aumento de la diferencia" entre experiencia y expectativa como sentenciaba Koselleck para la modernidad basada en el "progreso". Como en las tesis benjaminianas, el ángel de la historia que va de espalda al progreso mirando la muerte y los escombros sería la nueva y única metáfora. Parafraseando a Adorno, podríamos afirmar que escribir historia después de Auschwitz obliga a pensar un horizonte de expectativa que nunca podrá liberarse de su pasado. ¿Sería un retorno al topos de la historia magistra vitae? Koselleck explica que "un evento puede adquirir un significado estructural" (KOSELLECK, 2006, p. 140). Los eventos sólo se pueden narrar y las estructuras sólo se pueden describir, sostiene Koselleck. La investigación histórica busca "el esclarecimiento recíproco de los eventos por las estructuras y vice-versa” (KOSELLECK, 2006, p. 139). Así como Koselleck piensa la Revolución Francesa, Auschwitz es evento y estructura a la vez: culmina un proceso de radicalización política, representa un desvío perverso de una "racionalidad" y abre una exigencia político-moral hacia la memoria de las víctimas. Como premisa, podemos afirmar que el descubrimiento después de la guerra del sistemático y complejo sistema de exterminio que culminó en Auschwitz reconfiguró tanto el espacio de experiencia como el horizonte de expectativas de los historiadores: el problema de abordar la Segunda Guerra no tiene sólo una connotación metodológica, sino también - y necesariamente - moral y política. Vimos que pese a eso, Martin Broszat siguió apostando por un abordaje de cierto modo anacrónico (en términos de justificación política y metodológica) al "historizar" el cotidiano de los alemanes del régimen hitlerista sin tener en cuenta las política de exterminio o problematizarlas en su historiografía. La historia no se rige por la cronología, sino más bien al revés: el historiador debe "[...] poner al descubierto estructuras temporales acordes con las variadas formas del movimiento histórico" (KOSELLECK, 2013a, p. 73). Broszat 
ignoró el nuevo espacio de experiencia de los historiadores y se tuvo que enfrentar, como consecuencia, al daño moral apuntado por Friedländer, a saber, la nueva relación entre espacio de experiencia y horizonte de expectativas que representa la memoria del Holocausto.

En un texto de 1997, Koselleck advertía que el peligro de "atribuir un carácter inevitable a la historia no significa más que subordinarse y plegarse a ella para promover así una presunta necesidad" (KOSELLECK, 2013b, p. 112). Koselleck se refería a la arbitrariedad de cierta historiografía que interpreta eventos a partir de consecuencias posteriores que en su momento eran imprevisibles, como la batalla de Stalingrado. En el Historikerstreit, como vimos, tanto Nolte como Hillgruber trataron de justificar el nazismo ex post. Nolte recurre a la idea de una guerra civil contra el bolchevismo para justificar al nazismo y su frente oriental, al mismo tiempo que retoma la persecución a los judíos de la Unión Soviética para justificar o al menos relativizar los "antecedentes” de los campos de exterminio nazis. Decir que la Revolución Rusa fue una precondición para el nacionalsocialismo hace parte de una estrategia revisionista y relativizadora que no tiene miedo de asumir un anacronismo favorecido por la guerra fría. Hillgruber, en Zweierlei Untergang..., reproduce la épica del frente oriental y retoma el lenguaje burocrático para referirse a las "técnicas" de exterminio con gas en los campos. Estos historiadores parecen preocupados en apropiarse de la historia en el sentido que Koselleck llama "colectivo singular", entendido aquí en un sentido solemne, demasiado pretencioso de la "historia en sí". Habermas tiene razón en reprochar la estrategia conservadora de la "coalición". El espacio de experiencia que presupone Habermas parte de una crítica a la cultura político-partidaria, una disputa ideológica que se extendía desde los tiempos de Adenauer entre la SPD y la CDU. El acercamiento de la CDU a la política occidentalista y procapitalista de los Estados Unidos parecía propiciar al mismo tiempo que necesitaba una distorsión de la historia para legitimarse. Si la historia magistra vitae enseńa desde lo negativo, ¿ya no se habría aprendido lo suficiente con las simplificaciones revisionistas llevadas a cabo por la propaganda nazi? Habermas, sin embargo, sostiene su posición basándose en un horizonte de expectativas político-cultural al defender el patriotismo constitucional y una identidad moderna y posconvencional. Al buscar en ese horizonte de expectativas un "universalismo moral" y 
“experiencias de emancipación”, no deja, sin embargo, de recaer en una "filosofía de la historia". La pretensión de una evolución ilustrada de la sociedad moderna hace que Habermas fundamente su posición en una idea de "razón", o mejor, de racionalidad, un dispositivo cultural que presupone normas morales y pretensiones de validez del habla. Ese nuevo horizonte de expectativas tiene como espacio de experiencia el sentido público de la memoria colectiva: la diversidad de investigaciones históricas y la diversidad de posiciones políticas. Es un espacio de experiencia que necesita proyectar también hacia el presente y el pasado reciente una voluntad popular para una democracia postconvencional como norma social estructurante de los discursos. La instancia crítica de la historia se hace también a la medida que se la escribe y discute.

\section{THE PROBLEM OF NORMALIZATION IN THREE DEBATS: HISTORIZATION, HISTORIKERSTREIT AND GOLDHAGEN}

Abstract: In a context of historical revisionism is expected to have dispute about risks of political resignification on the issues discussed. However, when the object of discussion is political violence, it is usually more problematic challenge certain canon, given their moral burden in other areas of discursive validity. We call here "normalization" to the mode of "relativization" or resignification of certain collective guilt in relation to the political violence. Normalization is a discursive strategy that seeks to transcend their original intention of historiographical revision by winning the public area in its significant multiplicity. We will rebuild in this article three contexts where we can identify different modes of normalization. The first context concerns the debate between Broszat and Friedländer about the Historicization from Alltagsgeschichte (history of everyday). The second one enroll in the Historikerstreit or complaint of historians, and begins with a public debate in which Habermas responds to an Article of conservative historian Ernst Nolte, that compared Nazi Germany to the Soviet Stalinism in the context of the Cold War. Finally we deal with the debate on the bestseller by Daniel Goldhagen, widely echoed in the German public sphere, where an exaggerated "culturalization" of German antisemitism as the sole cause of the Holocaust stands out. Keywords: Historization. Historikerstreit. Debate Goldhagen. 


\section{Referencias}

ACHA, Omar. El pasado que no pasa: la Historikerestreit y algunos problemas actuales de la historiografía. Entrepasados, Revista de historia, v. 5, n. 9, p. 113139, 1995.

ADORNO, Theodor W. La idea de Historia Natural. In: Actualidad de la filosofía. Barcelona: Ed. Paidós, 1991. p. 103-134.

ALY, Götz. The Universe of Death and Torment. In: SHANDLEY, R. Unwilling Germans?: The Goldhagen Debate. Minneapolis: University of Minnesota Press, 1998. p. 167-174.

BALDWIN, Paul. The Historikerstreit in context. In: BALDWIN, P. (Comp.). Reworking the past: Hitler, the Holocaust and the Historians' debate. Boston: Beacon Press, 1990. p. 3-37.

BENZ, Wolfgang. Die Abwehr der Vergangenheit. Ein Problem nur für Historiker und Moralisten? In: DINER, D. (Hrsg.). Ist der Nationalsozialismus Geschichte?: $\mathrm{Zu}$ Historisierung und Historikerstreit. Frankfurt am Main: Fischer Verlag, 1988. p. 17-33.

BIRN, Ruth Bettina. Historiographical Review: Revising the Holocaust. The Historical Journal, v. 40, n. 1, p. 193-215, 1997.

BOCK, Gisela. Zwangssterilisation im Nationalsozialismus: Zur Rassenpolitik und Frauenpolitik. Opladen: Westdeutscher Verlag, 1986.

BRETON, Albert; WINTROBE, Ronald. The Boureaucracy of Murder Revisited. The Journal of Political Economy, v. 94, n. 5, p. 905-926, 1986.

BROSZAT, Martin. Plädoyer für eine Historisierung des Nationalsozialismus. Merkur, n. 39, p. 373-385, 1985.

. Zur Sozialgeschichte des deutschen Widerstands. Vierteljahrshefte für Zeitgeschichte, v. 34, n. 3, p. 293-309, 1986.

BROSZAT, Martin et al. (Hrsg.). Bayern in der NS-Zeit. Sechs Bänden. München: Oldenbourg Verlag, 1983.

BROSZAT, Martin; FRIEDLÄNDER, Saul. Um die Historisierung des Nationalsozialis-mus. Briefwechsel. Vierteljahrshefte für Zeitgeschichte, München-Berlin, v. 36, n. 2, p. 339-372, 1988.

BROWNING, Christopher R. La demonización no aclara nada. In: CANET, Manuel; RENAU, Elisa (Trad.). La controversia Goldhagen: los alemanes corrientes y el Holocausto. Valencia: Ed. Alfons el Magnànim, 1997. p. 14-20. (Biblioteca Debats, 21). 
El problema de la normalización...

Memoria alemana, interrogación judicial y reconstrucción histórica: escritura de la historia a partir del testimonio de posguerra. In: FRIEDLÄNDER, S. (Comp.). En torno a los limites de la representación. El nazismo y la solución final. Bernal: Ed. Universidad de Quilmes, 2007. p. 47-68.

. Los verdugos voluntarios de Daniel Goldhagen. In: FINCHELSTEIN, F. (Comp.). Los alemanes, el Holocausto y la culpa colectiva: el debate Goldhagen. Buenos Aires: EUDEBA, 1999. p. 115-135.

COHEN, Stanley. Estados de negación. Buenos Aires: Departamento de Publicaciones de la Facultad de Derecho, Universidad de Buenos Aires, 2005.

DINER, Dan. Zwischen Aporie und Apologie. Über Grenzen der Historisierung des Nationalsozialismus. Gewerkschaftliche Monatshefte, v. 87, n. 3, p. 153-159, 1987.

FEST, Joachim. Die geschundete Erinnerung. Zur Kontroverse über die Unvergleichberkeit und Vergangenheitsbewältigung in der Bundesrepublik. FAZ, 29 de Agosto de 1986. In: AUGSTEIN, R. (Org.). Historikerstreit. Die Dokumentation der Kontroverse um die Einzigartigkeit der nationalsozialistischen Judenvernichtung. 8. Aufl. München: Piper Verlag, 1991. p. 100-112.

FINCHELSTEIN, Federico. El canon del Holocausto. Buenos Aires: Prometeo Libros, 2010.

. El debate Goldhagen en contexto. Memorias colectivas y representaciones críticas. In: FINCHELSTEIN, F. (Comp.). Los alemanes, el Holocausto y la culpa colectiva: el debate Goldhagen. Buenos Aires: EUDEBA, 1999. p. 31-72.

FINKELSTEIN, Norman. Daniel Jonah Goldhagen's,Crazy' Thesis: A Critique of Hitler's Willing Executioners. New Left Review, London, n. 224, p. 39-88, July 1997.

. La industria del Holocausto. Madrid: Ed. Akal, 2014.

FRIEDLÄNDER, Saul. Some reflections on the historicization of national socialism. Tel Aviver Jahrbuch für deutsche Geschichte, n. 16, p. 310-324, 1987.

FURET, François. Pensar la revolución francesa. Barcelona: Ediciones Petrel, 1980.

GOLDHAGEN, Daniel J. Los verdugos voluntarios de Hitler: los alemanes corrientes y el Holocausto. Madrid: Ed. Taurus, 1997.

GOLDHAGEN - Ein Quellentrickser? Der Spiegel, n. 33, p. 156-158, 1997.

HABERMAS, Jürgen. ¿Aprender de la historia? In: . Más allá del Estado nacional. Madrid: Ed. Trotta, 1997a. p. 39-48.

. Concerning the public use of history. New German Critique, v. 44, p. 40-50, Spring/Summer 1988a. 
. Consciencia histórica e identidad postradicional. In: Identidades. Madrid: Ed. Tecnos, 1989a. p. 83-110.

. Die Kulturkritik der Neokonservativen in den USA und in der Bundesrepublik. In: . Die Moderne: ein unvollendetes Projekt: Philosophisch-politische Aufsätze (1977-1992). Leipzig: Reclam, 1992. p. 75-104.

. Geschichtsschreibung und Geschichtsbewusstsein. FAZ, 11 ago. 1986. . Identidad nacional e identidad postnacional. Entrevista con J. M. Ferry. In:__. Identidades. Madrid: Ed. Tecnos, 1989b. p. 111-121.

. A kind of settlement of damages (Apologetic tendencies). New German Critique, v. 44, p. 25-39, Spring/Summer 1988b.

. Respuestas a las preguntas de una comisión de encuestas del parlamento.

In: . Más allá del Estado nacional. Madrid: Ed. Trotta, 1997b. p. 49-83. Sobre o emprego público da historia. In: . A constelação Pósnacional. São Paulo: Ed. Littera Mundi, 2001. p. 37-49.

. Theorie des kommunikativen Handelns. Band I und II. Frankfurt: Suhrkamp Verlag, 1981.

HILLGRUBER, Andreas. Zweierlei Untergang: Die Zerschlagung des Deutschen Reiches und das Ende des europäischen Judentums. Berlin: Siedler Verlag, 1986. JÄGER, Herbert. Die Widerlegung des funktionalistischen Täterbildes. Daniel Goldhagens Beitrag zur Kriminologie des Völkermords. Mittelweg, n. 36, p. 220 237, feb./mar. 1997.

KAILITZ, Stephen. Einleitung. In: . (Comp.). Die Gegenwart der Vergangenheit: Der "Historikerstreit" und die Deutsche Geschichtspolitik. Wiesbaden: VS Verlag für Sozialwissenschaften, 2008. p. 7-14.

KERSHAW, Ian. La dictadura nazi: principales controversias en torno a la era de Hitler. Buenos Aires: Ed. Siglo XXI, 2013.

KOSELLECK, Reinhart. Futuro passado: Contribuição à semântica dos tempos históricos. Rio de Janeiro: Ed. PUC do Rio, 2006.

- ¿Para qué todavía investigación histórica? In: Sentido y repetición en la historia. Buenos Aires: Ed. Hydra, 2013a. p. 39-78.

Sobre el sentido y el sinsentido de la historia. In: tición en la historia. Buenos Aires: Ed. Hydra, 2013b. p. 79-124. Sentido y repeLACAPRA, Dominick. Escribir la historia, escribir el trauma. Buenos Aires: Nueva Visión, 2005. 
El problema de la normalización...

. Representar el Holocausto: reflexiones sobre el debate de los historiadores. In: FRIDLÄNDER, S. (Comp.). En torno a los limites de la representación: El nazismo y la solución final. Bernal: Ed. Universidad de Quilmes, 2007. p. 171-198. LÜDTKE, Alf. De héroes de la resistencia a los coautores. In: CASTELLS, L. (Comp.). La historia de la vida cotidiana. Madrid: Ed. Marcial Pons, 1995. p. 49-100.

MASON, Timothy. Nazism, Fascism and the Working Class. Cambridge: Cambridge University Press. 1995.

. Social Policy in the Third Reich: The Working Class and the 'National Community'. Oxford: Berg Editorial, 1993.

MOMMSEN, Hans. La sutil pátina de la civilización. In: CANET, Manuel; RENAU, Elisa (Trad.). La controversia Goldhagen: Los alemanes corrientes y el Holocausto. Valencia: Ed. Alfons el Magnànim, 1999. p. 100-118. (Biblioteca Debats, 21).

. National Socialism. Continuity and Change. In: LAQUEUR, W. (Ed.). Fascism: A Readers Guide. Harmondsworth: Penguin Books, 1976. p. 179-210.

MOSES, A. D. Structure and Agency in the Holocaust: Daniel J. Goldhagen and His Critics. History and Theory, v. 37, n. 2, p. 194-219, May 1998.

NOLTE, Ernst. El fascismo en su época: Action Française, Fascismo y Nacionalsocialismo. Madrid: Ed. Península, 1967.

. La guerra civil europea, 1917-1945: Nacionalsocialismo y bolchevismo. México, DF: Fondo de Cultura Económica, 1994.

OFFE, Claus. Democracy against the Welfare-State? Structural Foundations of Neoconservative Political Opportunities. Political Theory, v. 15, n. 4, p. 501-537, 1987.

PEUKERT, Detlev J. K. Alltag und Barbarei. Zur Normalität des Dritten Reiches. Gewerkschaftliche Monatshefte, v. 87, n. 3, p. 142-153, 1987.

RABINBACH, Anson. From explosion to erosion. Holocaust Memorialization in America since Bitburg. History and Memory, v. 9, n. 1/2, p. 226-255, 1997.

RAUSCHENBERG, Nicholas. Entre Adorno y Habermas. Notas sobre la experiencia intelectual de Albrecht Wellmer. Revista Controvérsia, v. 7, n. 1. p. 38-60, 2011.

SITTON, John. Habermas y la sociedad contemporánea. México, DF: Fondo de Cultura Económica, México, 2006.

STÜRMER, Michael. Kein Eigentum der Deutschen: die deutsche Frage. In: WEIDENFELD, W. (Hrsg.). Die Identität der Deutschen. Bonn: Goldmann Verlag, 1983. p. 81-92.

Anos 90, Porto Alegre, v. 23, n. 43, p. 443-487, jul. 2016 
TRAVERSO, Enzo. El pasado, instrucciones de su uso. Buenos Aires: Prometeo Libros, 2011.

ULRICH, Volker. Los verdugos voluntarios de Hitler. In: CANET, Manuel; RENAU, Elisa (Trad.). La controversia Goldhagen: Los alemanes corrientes y el Holocausto. Valencia: Ed. Alfons el Magnànim, 1999. p. 129-135. (Biblioteca Debats, 21).

WEHLER, Hans-Ulrich. Como una espina clavada. In: CANET, Manuel; RENAU, Elisa (Trad.). La controversia Goldhagen: Los alemanes corrientes y el Holocausto. Valencia: Ed. Alfons el Magnànim, 1997a. p. 39-51. (Biblioteca Debats, 21).

. 'Deutscher Sonderweg' oder allgemeine Probleme des westlichen Kapitalismus? Zur Kritik an einigen 'Mythen deutscher Geschichtsschreibung'. Merkur, v. 35, n. 5, p. 478-487, 1981.

. The German Empire 1871-1918. Oxford: Berg, 1997b.

Recebido em: 20/ 01/ 2015

Aprovado em: 15/ 07/ 2016 